\title{
Lin28A promotes the proliferation and stemness of lung cancer cells via the activation of mitogen-activated protein kinase pathway dependent on microRNA let-7c
}

\author{
Rui Zhang ${ }^{1,2}$, Pengpeng Liu ${ }^{1,2}$, Xiao Zhang ${ }^{1,2}$, Yingnan Ye ${ }^{1,2}$, Jinpu Yu ${ }^{1,2}$ \\ ${ }^{1}$ Cancer Molecular Diagnostics Core, Tianjin Medical University Cancer Institute \& Hospital, National Clinical Research Center of Cancer, Key \\ Laboratory of Cancer Prevention and Therapy, Key Laboratory of Cancer Immunology and Biotherapy, Tianjin, China; ${ }^{2}$ Tianjin's Clinical Research \\ Center for Cancer, Tianjin, China \\ Contributions: (I) Conception and design: J Yu; (II) Administrative support: None; (III) Provision of study materials or patients: None; (IV) Collection \\ and assembly of data: R Zhang; (V) Data analysis and interpretation: R Zhang; (VI) Manuscript writing: All authors; (VII) Final approval of \\ manuscript: All authors. \\ Correspondence to: Jinpu Yu, PhD. Cancer Molecular Diagnostics Core, Tianjin Medical University Cancer Institute \& Hospital, National Clinical \\ Research Center of Cancer, Key Laboratory of Cancer Prevention and Therapy, Key Laboratory of Cancer Immunology and Biotherapy, Tianjin, \\ China. Email: jyu@tmu.edu.cn.
}

Background: Among patients with lung cancer, metastatic and relapsed cases account for the largest proportion of disease-associated deaths. Tumor metastasis and relapse are believed to originate from cancer stem cells (CSCs), which have the capacity to be highly proliferative and invasive. In our previous studies, we established a conditional basement membrane extract-based (BME-based) 3-dimensional (3D) culture system to mimic the tumor growth environment in vivo and further amplified lung cancer stem cells (LCSCs) in our system. However, the molecular mechanisms of LCSC amplification and development in our 3D culture system have not been fully uncovered.

Method: We established the conditional 3D culture system to amplify LCSCs in other lung cancer cell lines, followed by examining the expression of Lin28A and let-7 microRNAs in them. We also explored the expression of Lin28A and let-7 microRNAs in LCSCs from clinical lung cancer tissue samples and even analyzed the correlation of Lin28A/let-7c and patients' survival outcomes. We further constructed A549 cells either knockdown of Lin28A or overexpression of let-7c, followed by investigating stemness marker gene expression, and stemness phenotypes including mammosphere culture, cell migration and invasion in vitro, as well as tumorigenicity in vivo.

Results: Here, we observed that Lin28A/let-7c was dysregulated in LCSCs in both the 3D culture system and lung cancer tissues. Further, the abnormal expression of Lin28A/let-7c was correlated with poor survival outcomes. Via the construction of A549 cells with let-7c over-expression, we found that let-7c inhibited the maintenance of LCSC properties, while the results of Lin28A knockdown showed that Lin28A played a critical role in the enrichment and proliferation of LCSCs via mitogen-activated protein kinase (MAPK) signaling pathway. Importantly, we found that LCSCs with knockdown of Lin28A or over-expression of let7c exhibited inhibited carcinogenesis and disrupted expansion in vivo.

Conclusions: Our study uncovered the functions and mechanisms of the Lin28A/let-7c/MAPK signaling pathway in promoting the proliferation and cancer stemness of LCSCs, which might be a potential therapeutic target for reducing and even eliminating LCSCs in the future.

Keywords: Lin28A; cancer stemness; lung cancer; MAPK pathway; let-7c

Submitted Apr 11, 2021. Accepted for publication Jun 04, 2021.

doi: 10.21037/atm-21-2124

View this article at: https://dx.doi.org/10.21037/atm-21-2124 


\section{Introduction}

Lung cancer ranks among the highest-incidence malignant tumors globally and is associated with high morbidity and fatality rates $(1,2)$. Although molecular classification and targeted therapy of lung cancer has achieved significant progress in recent years, patients have limited benefit from regular therapies and the 5-year survival rate of the disease has not been effectively improved $(3,4)$. Metastasis and recurrence are the leading causes of disease-related lung cancer deaths $(2,5)$. Recently, the roles of cancer stem cells (CSCs) in the occurrence and development of tumors have received considerable attention (6-8). Lung cancer stem cell (LCSC) constitutes a highly carcinogenic cell subgroup, which exhibits similar biological characteristics as normal tissue stem cells, including an unlimited self-renewal ability, an extensive proliferative ability and a capacity to generate differentiated progeny $(9,10)$. More and more evidences show that LCSCs play a crucial role in tumor progression, metastasis and drug resistance (11-13). Current anticancer therapies cannot eradicate LCSC clones. Instead, it facilitates to expand the LCSC pool and select for drugresistant LCSC clones, leading to treatment resistance and subsequent recurrence in these patients (14-16).

However, currently, no large-scale clinical treatment targeting LCSCs exists, mainly owing to the challenges of LCSC isolation and purification. Moreover, the molecular mechanisms regulating LCSCs are still not clear. Therefore, the establishment of a culture method for LCSC enrichment and further illumination of the molecular mechanisms involved in the occurrence and development of LCSCs would be of great significance to the screening of more effective drugs to target LCSCs in lung cancer clinical research.

Since under 2-dimensional (2D) culture, cancer cells grow in a single layer and might differentiate and lose their stemness phenotypes rapidly $(17,18)$, simulating the local tumor microenvironment in vitro using 2D culture method is challenging. Therefore, $2 \mathrm{D}$ culture is not suitable for mechanistic research and clinical transformation of LCSCs $(19,20)$. Our previous work established a 3-dimensional (3D) culture system based on basement membrane extractbased (BME) with the addition of fibroblast growth factor 1 (FGF1) and insulin-like growth factor 1 (IGF1), which could provide the cultured cells with vital growth factors (21). Furthermore, the 3D structure facilitated the formation of tissue-specific structures to effectively mimic a local microenvironment in vivo. The $3 \mathrm{D}$ culture system we established could effectively achieve the enrichment and amplification of LCSCs. In our 3D culture system, FGF1 and IGF1 supported LCSC amplification and cancer stemness by activating mitogen-activated protein kinase (MAPK) signaling pathway. However, the molecular mechanisms of the amplification and development of LCSCs in our 3D culture system are still not entirely clear.

An increasing amount of research has evidenced microRNAs (miRNAs), as small non-coding RNAs responsible for the negative regulation of posttranscriptional gene expression (22-24), to be critical regulatory players in cancer cell stemness via their targeting of different genes (25-27). In lung cancer, miRNAs have been shown to be the chief molecular regulators involved in maintaining the metastatic, drugresistant, and self-renewing properties of LCSCs through their effective targeting of vital genes involved in various signaling pathways $(28,29)$. The combination of miRNAs with antitumor drugs has been associated with positive preclinical outcomes in multiple translational works (30-33). Therefore, miRNAs might serve as promising targets for eliminating CSCs.

Lin28A is one of the reprogramming factors to induce pluripotency in adult human fibroblast cells (34), which has been reported to be over-expressed in advanced human malignancies and play an important role in the maintenance of CSCs $(35,36)$. Previous studies showed that miRNA let7 binds to the 3' UTR of Lin28A mRNA to negatively regulate Lin28A expression, while Lin28A itself blocks let-7 expression, thereby establishing a double negative feedback loop (36). However, none study focusing on the expression and roles of Lin28A in LCSCs has ever been reported.

In this study, to investigate the most critical miRNAs involved in the regulation of cancer cell stemness in our $3 \mathrm{D}$ culture system, we searched 2 popular miRNA databases and filtered out 25 candidate miRNAs which might have abnormal expression levels in lung cancer. We examined the levels of these 25 miRNAs in different lung cancer cell lines cultured in our 3D system. The levels of let7 miRNAs, especially let-7c, were significantly downregulated in LCSCs amplified in our $3 \mathrm{D}$ culture system. In previous studies, a reduced expression of let-7c was common in cancer and was usually correlated with a poor patient outcome (37-39). Overexpressing let-7 expression was found to inhibit sphere formation and carcinogenesis of CSCs, and reduce the proportion of undifferentiated cells; similarly, suppressing let-7 enhanced self-renewal and prompted aggressiveness (40-44). However, some studies 
have revealed that let-7c can also enhance tumor invasion and growth via the DVL3/ $\beta$-catenin axis (45). Although let$7 \mathrm{c}$ is known to play an important dual role in regulating the tumorigenic and metastatic abilities of cancer cells, its role in LCSC development is still not very clear. Therefore, this study explored the functions of let-7c during the occurrence and development of lung cancer using LCSCs.

We present the following article in accordance with the ARRIVE reporting checklist (available at https://dx.doi. org/10.21037/atm-21-2124).

\section{Methods}

\section{Protocol registration}

A protocol was prepared before the study with registration in 81702280 (the National Natural Science Foundation of China).

\section{Patient information}

A total of 125 patients with lung adenocarcinoma (LUAD; $\mathrm{N}=125$ in total) who received partial lung resection in Tianjin Medical University Cancer Institute and Hospital's Department of Lung Cancer. We also obtained 4 LUAD tissue specimens ( $\mathrm{N}=4$ in total), from which $\mathrm{CD} 326^{+} \mathrm{CD} 44^{+} \mathrm{CD} 24^{-}$cells were isolated by flow sorting. None of the patients had received therapies, such as chemotherapy or radiotherapy, ahead of their operation. The Ethics Committee of Tianjin Medical University granted approval for this study (Approved No.: Ek2017055). Each experiment was carried out in adherence with the principles of the Declaration of Helsinki (as revised in 2013). Each patient gave written informed consent before participating in the study.

\section{Cell lines and cell culture}

The human LUAD cell lines A549 and H1299, and the lung squamous cell carcinoma (LUSC) cell lines NCI-H520 and SK-MES-1 (Chinese Academy of Medical Sciences' tumor cell library) were subjected to short tandem repeat DNA profiling and mycoplasma testing. For the 2D culture system, A549, H1299, and NCI-H520 cells were cultured in Roswell Park Memorial Institute (RPMI)-1640 Medium (Gibco BRL, Grand Island, NY, USA) supplemented with $10 \%$ fetal bovine serum and $1 \%$ penicillin/streptomycin (Gibco BRL, Grand Island, NY, USA) at $37^{\circ} \mathrm{C}$ under
$5 \% \mathrm{CO}_{2}$. SK-MES-1 was cultured in Minimal Essential Medium containing $10 \%$ fetal bovine serum, 1\% nonessential amino acids, $1 \mathrm{mM}$ sodium pyruvate, and $1 \%$ penicillin/streptomycin. For 3D culture, firstly, the addition of $50 \mu \mathrm{L} /$ well Cultrex ${ }^{\circledR}$ Basement Membrane Extract (BME, R\&D Systems, MN, USA) was made to 96-well plates, which were then kept at $37^{\circ} \mathrm{C}$ for 1 hour, to form a reconstituted basement membrane with specific thickness and stiffness. Then, the BME-coated plate was seeded with suspended cells $\left(1 \times 10^{4}\right.$ cell/200 $\mu \mathrm{L} /$ well $)$, which were examined at 3-day intervals. Cell aggregate was generated through migration of cells into the inner BME layer. At day 3 of culturing, the simultaneous addition of $20 \mathrm{ng} / \mathrm{mL}$ FGF1 and $50 \mathrm{ng} / \mathrm{mL}$ IGF1 was made to complete medium as described previously (21). In each experiment, we established 3 identical wells for each group of cells.

\section{Lentivirus construction}

For let-7c over-expression lentivirus construction, the fulllength cDNA of human hsa-let-7c was amplified by PCR with forward primer and reverse primers containing EcoRI and BamHI sites, respectively. The primers sequence were FP: Ata gaa ttc GCA TCC GGG TTG AGG TAG TAG GTT GTA TGG TTT AGA GTT ACA CCC TGG GAG TTA; RP: Ata gga tcc AAA AAA TGC TCC AAG GAA AGC TAG AAG GTT GTA CAG TTA ACT CCC AGG GTG TAA C. Then the amplified let-7c fragment was inserted into pHBLV-CMV-MCS-EF1-ZsGreenT2A-Puro lentiviral vectors (Hanbio Co., Ltd., Shanghai, China), and the constructed positive plasmid was confirmed by DNA sequencing. The recombinant lentivirus with let-7c sequence was generated by cotransfection in A549 cells as previously described (46). For Lin28A knockdown lentivirus construction, specific shRNA sequence based on the sequence of Lin28A (Gene ID: 79727, on NCBI) was designed. The synthesized Lin28A shRNA was inserted into plvx-U6-CMV-RFP-P2A-BSD lentiviral vectors. The lentivirus was generated as described above.

\section{Mice and xenograft model construction}

Female non-obese diabetic/severe combined immunodeficiency mice ( 7 weeks old; $17-18 \mathrm{~g}$ ) were obtained from Beijing SPF Biotechnology Co., Ltd. (Beijing, China) and randomly divided into two groups. The animals were kept in a specific pathogen-free animal facility at Tianjin Medical University Cancer Hospital and Institute. 
We obtained different types of cells carrying constructed lentiviruses $\left(\mathrm{A} 549-3 \mathrm{D}+\mathrm{F}, \mathrm{A} 549^{\text {OV-let-7c }}-3 \mathrm{D}+\mathrm{F}\right.$, and $\mathrm{A} 549^{\text {sh- }}$ Lin28A $-3 \mathrm{D}+\mathrm{F} ; \mathrm{N}=5$ in each group) and resuspended $5 \times 10^{4}$ cells in $100 \mu \mathrm{L}$ of PBS with Matrigel, followed by administered the cells into the flanks of NOD-SCID mice via subcutaneous injection. All procedures involving animals received approval from the Ethics Committee for Animal Experiments at Tianjin Medical University Cancer Hospital and Institute (Approved No.: NSFC-AE-2020101) and adhered to the National Institutes of Health Guide for the Care and Use of Laboratory Animals.

\section{Flow cytometry analysis}

Labelling of LCSCs ( $\mathrm{N}=5$ in each group) was performed using fluorescein isothiocyanate (FITC) anti-human CD326, APC anti-human CD44, and PE anti-human CD24 antibodies (BD Biosciences, San Jose, CA, USA). We selected isotype-matched immunoglobulin G1 antibodies (BD Biosciences, San Jose, CA, USA) to serve as a negative control. A BD FACS CantoTM II flow cytometer was employed for flow cytometry. The gating strategy used was described in our previous work (21).

\section{Statistical analyses}

Animals were excluded from a study for the reason of illness or mortality. And data points were excluded from analyses for the reason of biologically implausible values. Data were statistically analyzed with SPSS 20.0 and GraphPad Prism 5.0 software following the manufacturers' instructions. Measurement data were expressed as means \pm standard deviations. We analyzed correlations between 2 datasets using Spearman's correlation coefficient. One- and 2-way analysis of variance with subsequent Bonferroni posthoc tests was used for comparisons between 2 groups. Cumulative survival was determined via the Kaplan-Meier method. All data were normally distributed. $\mathrm{P}<0.05$ was taken to indicate a statistically significant result.

More detailed methods can be found in the Supplemental data (Appendix 1).

\section{Results}

Lin28A/let-7c was dysregulated in LCSCs from the BMEbased $3 D$ culture system

In our previous studies, we used FGF1 and IGF1 to establish the conditional 3D culture based on BME with growth factors $(3 \mathrm{D}+\mathrm{F})$ for LCSC amplification in A549 cells (A549-3D+F cells) in vitro (21). To investigate the most critical miRNA(s) involved in the regulation of stemness in A549-3D+F cells, we firstly filtered candidate miRNAs in online databases. We searched the Human miRNA Disease Database (HMDD, version 3.2) (47), in which experiment-supported evidence for human miRNA and disease associations is curated. We identified 305 miRNAs which are dysregulated in lung cancer, including 108 miRNAs that have direct causality with lung cancer. We also searched for miRNAs on the OncomiR database (48), and this search retrieved 379 miRNAs associated with lung cancer development, as well as 109 miRNAs associated with survival outcome of lung cancer. We obtained 25 differentially expressed miRNAs from the intersection of the 2 databases (Figure S1). Then, we collected the pellets of A549 cells from the 2D culture (A549-2D cells) and A549-3D+F cells, and performed quantitative-polymerase chain reaction (qPCR) to compare the RNA levels of the 25 differentially expressed miRNAs. In comparison with A5492D cells, A549-3D+F cells exhibited dramatic increases in the levels of a number of miRNAs, such as miR-873, miR31, miR-582, miR-196b, and miR-212. Meanwhile, some miRNAs were significantly decreased in A549-3D+F cells, including miR-99a, miR-145, miR-181c, miR-30a, miR29b, let-7g, let-7f, miR-490, and let-7c. Among these miRNAs, let-7c, let-7f, and let-7g, which belong to the same miRNA family, had the lowest expression levels in A549-3D+F cells (Figure 1A).

To investigate which biological processes let-7 miRNAs are involved in, we used DIANA-miRPath v2.0 (49), which is another popular database which can predict the pathways in which miRNA targets are enriched using the DIANAmicroT-CDS algorithm and/or experimentally validated miRNA interactions derived from DIANA-TarBase v6.0. The results showed the let-7 miRNA target genes to be enriched in signaling pathways regulating the pluripotency of stem cells (Figure 1B), indicating that let-7 miRNAs are involved in the regulation of cancer stemness.

We then focused on the functions of let-7c, considering let-7c miRNAs had the lowest expression in A549-3D+F cells. We searched TargetScan to identify let-7c target genes (50), and found 1207 transcripts which are potentially targeted by let-7c. Among the top 10 target genes, Lin28A/ $\mathrm{B}$ (Figure 1C), which is a reprogramming factor, has been observed to induce pluripotency in adult human fibroblast cells (51). The dual-luciferase reporter assay revealed that 
A

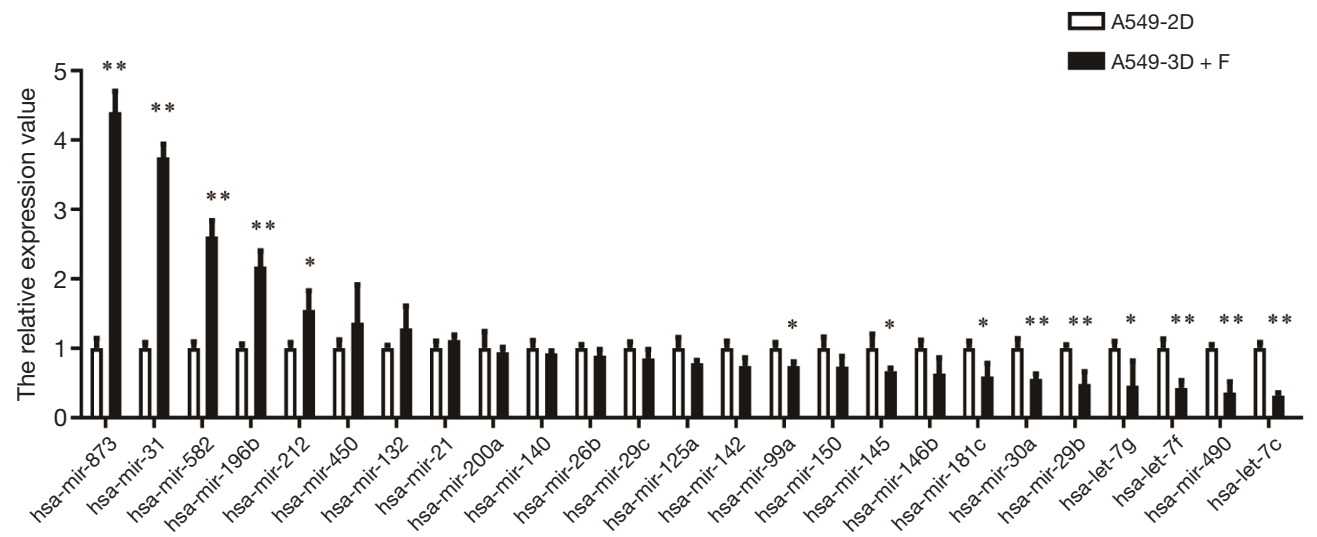

B

B DIANA-microT-CDS
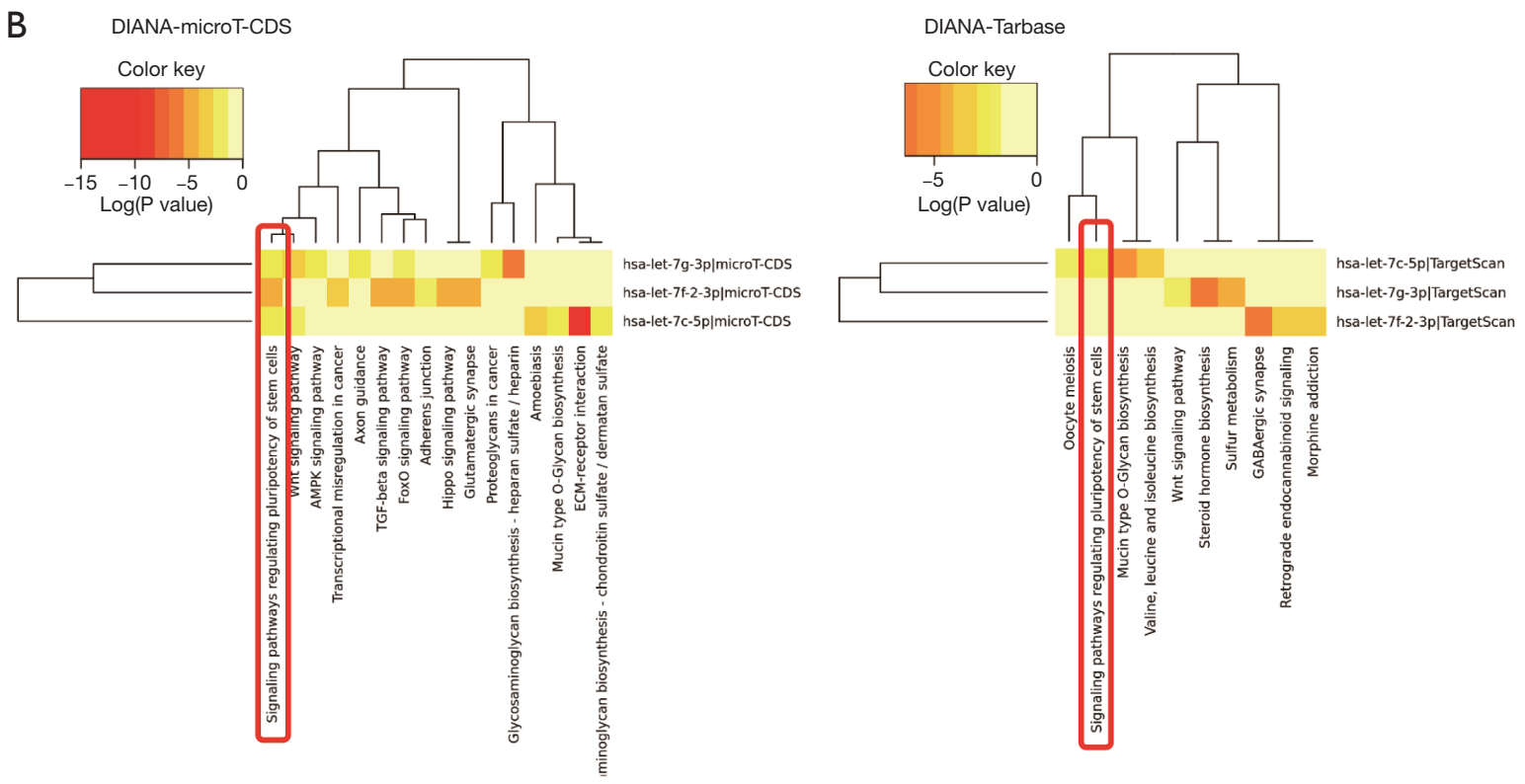

C

TargetScan

D

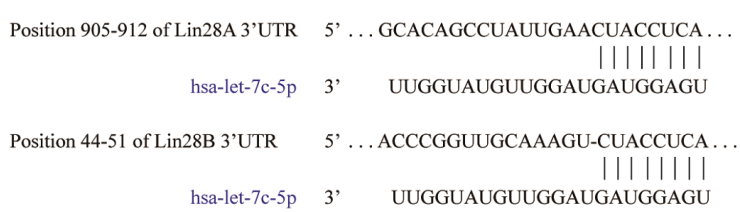

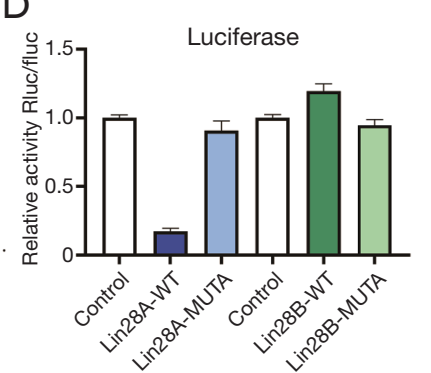

E $\quad$ 口A549-2D

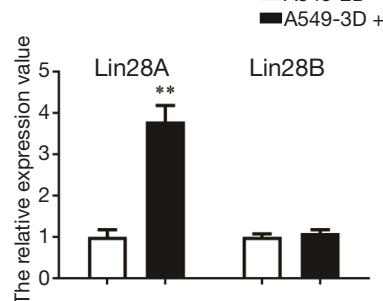

Figure 1 Lin28A/let-7c was dysregulated in lung cancer stem cells (LCSCs) from the basement membrane extract-based (BME-based) 3-dimensional (3D) culture system. (A) The realtime quantitative PCR (RT-qPCR) results of 25 candidate differentially expressed microRNAs (miRNAs). All of the results shown for A549 cells from the 3D culture with growth factors (A549-3D+F cells) are the relative expression values in comparison with A549 cells from the 2D culture (A549-2D cells). (B) Biological processes in which the let-7 miRNAs are enriched as indicated on the DIANA database. (C) Let-7c targets Lin28A and Lin28B, as indicated by TargetScan. (D) Dual-luciferase reporter assay using HEK-293T cells co-transfected with psiCheck2.0-Lin28A/B vector/psiCheck2.0-Lin28A/B-mutant vector and let-7c mimic/the negative control of let-7c mimic. (E) Results of RT-qPCR of Lin28A and Lin28B in A549-2D and A549-3D+F cells. The data are displayed as mean $\pm \mathrm{SD} .{ }^{*}$ and ${ }^{*}$ indicates $\mathrm{P}<0.05$ and $\mathrm{P}<0.01$ between the groups, respectively. 
the relative luciferase activity of Lin28A 3'UTR, rather than Lin28B 3'UTR, was significantly decreased in HEK293T cells transfected with let-7c mimic (Figure 1D). Then, we compared the transcription levels of Lin28A/B between A549-2D and A549-3D+F cells. Consistent with the results of the luciferase reporter assay, the transcription level of Lin28B showed no difference between the 2 groups, whereas the transcription level of Lin28A was significantly up-regulated in A549-3D+F cells (Figure 1E). All the above results indicated that Lin28A/let-7c was dysregulated in LCSCs from the BME-based 3D culture system, suggesting that Lin28A/let-7c might play roles in the development of LCSCs.

\section{Lin28A/let-7c was expressed abnormally in LCSCs from other 3D cultured lung cancer cell lines}

We further attempted to establish $3 \mathrm{D}+\mathrm{F}$ culture to amplify LCSCs in another LUAD cell line, H1299. As before, we applied the co-stimulation of FGF1 and IGF1 in the BMEbased $3 \mathrm{D}$ system to establish our $3 \mathrm{D}+\mathrm{F}$ culture. In the spheroid formation assay, we could hardly observe apparent spheroids in H1299 cultured in 2D culture system (H12992D) (Figure 2A, left panel); however, several large spheroids were observed in H1299 cultured in 3D+F system (H1299$3 \mathrm{D}+\mathrm{F}$ ) (Figure $2 \mathrm{~A}$, right panel). The migration ability of H1299-2D and H1299-3D+F cells was evaluated via wound healing experiment. After 48 hours, the H1299-3D+F cell wound closure rate displayed a significant increase compared to that of H1299-2D cells (Figure 2B).

Further, we detected the levels of let-7 miRNAs and Lin28A in H1299-2D and H1299-3D+F cells. Consistent with the results in A549 cells, let-7c, let-7f, and let$7 \mathrm{~g}$ were significantly down-regulated in $\mathrm{H} 1299-3 \mathrm{D}+\mathrm{F}$ cells compared to H1299-2D cells (Figure 2C), while the protein expression of Lin28A was significantly up-regulated in H1299-3D+F cells (Figure 2D), indicating that the expression loop of let-7c/Lin28A was largely dysregulated in LUAD CSCs.

We also used the $3 \mathrm{D}+\mathrm{F}$ culture system to amplify LCSCs in the LUSC cell line H520. The sphere formation and wound healing assay results also revealed that cells cultured in the $3 \mathrm{D}+\mathrm{F}$ system exhibited more stemness characteristics than those cultured in the $2 \mathrm{D}$ system (Figure $2 E, F$ ), implying that we had successfully and efficiently enriched and enhanced the stemness of LCSCs in both LUAD and LUSC cell lines in our $3 \mathrm{D}+\mathrm{F}$ system. Furthermore, as expected, let-7 miRNAs showed down-regulation in cells cultured in the $3 \mathrm{D}+\mathrm{F}$ system compared to those cultured in the 2D system (Figure 2G), while the protein expression levels of Lin28A were significantly up-regulated in cells cultured in the $3 \mathrm{D}+\mathrm{F}$ system (Figure $2 \mathrm{H}$ ). Besides that, we applied the $3 \mathrm{D}+\mathrm{F}$ culture system to another LUSC cell line SK-MES-1, and observed the similar results in SKMES-1 (Figure 2I, $\mathcal{7}, K, L$ ). All the results above indicated that the abnormal expression of the let- $7 \mathrm{c} / \mathrm{Lin} 28 \mathrm{~A}$ loop was a common phenomenon in different subtypes of LCSCs.

\section{Lin28A/let-7c was dysregulated in LCSCs from lung cancer tissues and its abnormal expression was correlated with poor survival outcomes}

As CD $326^{+}, \mathrm{CD}_{4} 4^{+}, \mathrm{CD} 24^{-}$has been reported as the characteristic phenotypic markers on the cell surface of LCSCs $(52,53), \mathrm{CD} 326^{+} \mathrm{CD} 44^{+} \mathrm{CD} 24^{-}$cells were termed as the LCSCs in this research. Four clinical LUAD tissue samples were collected, from which $\mathrm{CD} 326^{+} \mathrm{CD} 44^{+} \mathrm{CD} 24^{-}$ cells were isolated (Figure $3 A$ ) by flow sorting. Then, we examined the RNA levels of let-7c, let-7f, and let$7 \mathrm{~g}$ individually. Consistent with the results for LCSCs from the $3 \mathrm{D}$ culture system, the levels of let-7c were significantly decreased in the $\mathrm{CD} 326^{+} \mathrm{CD} 44^{+} \mathrm{CD} 24^{-}$group compared with the non-CD $326^{+} \mathrm{CD} 44^{+} \mathrm{CD} 24^{-}$group (Figure 3B). Furthermore, the expression levels of Lin28A were significantly up-regulated in $\mathrm{CD} 326^{+} \mathrm{CD} 44^{+} \mathrm{CD} 24$ cells, whereas the expression levels of Lin28B showed no difference between the 2 groups (Figure 3C).

We then collected 125 LUAD tumor tissue specimens from Tianjin Medical University Cancer Institute and Hospital (Table 1) and explored let-7c/Lin28A's association with patients' overall survival (OS) by performing qPCR. The patients were stratified into 2 groups according to the transcription levels of either let-7c or Lin28A, following which their survival was analyzed by applying the KaplanMeier method. Low levels of let-7c, as well as a high expression of Lin28A, were found to be correlated with poor survival outcomes (Figure 3D,E). Furthermore, Spearman's rank correlation revealed the levels of let-7c to be significantly negatively correlated with those of Lin28A in the clinical LUAD tumor samples (Figure $3 F$ ).

To further explore the effects of Lin28A in LUAD occurrence and development in a larger group of samples, we analyzed data from The Cancer Genome Atlas (TCGA). We found the level of Lin28A in LUAD primary tissue samples to show a significant increase compared to that in the matched adjacent non-tumor tissue samples 
A

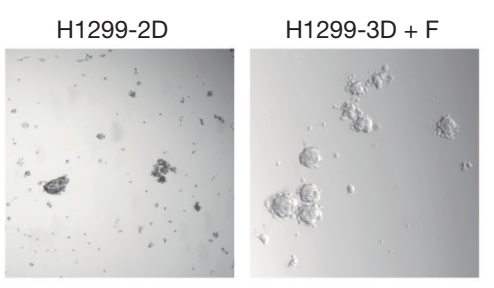

E

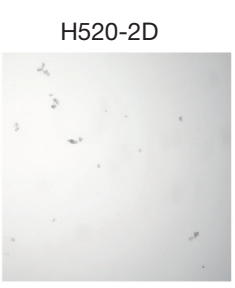

I

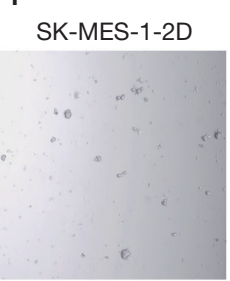

$H 520-3 D+F$
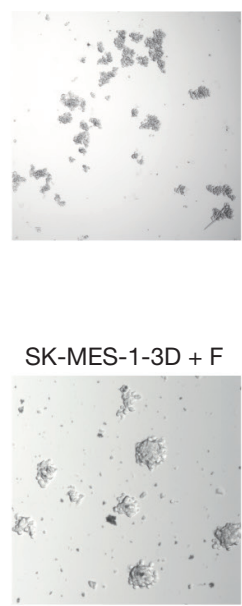

B

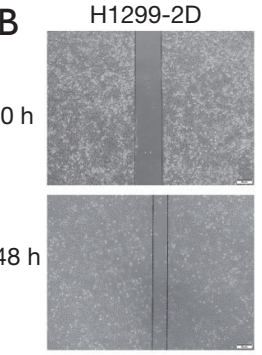

F H520-2D

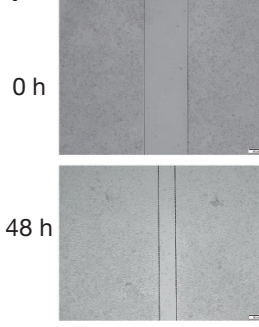

J

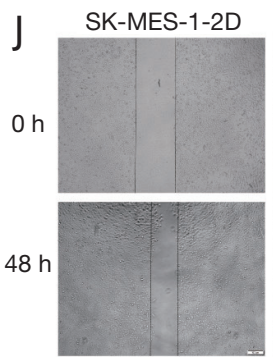

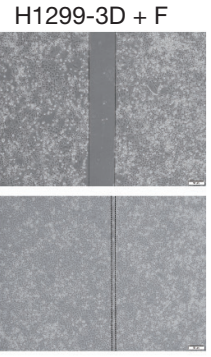

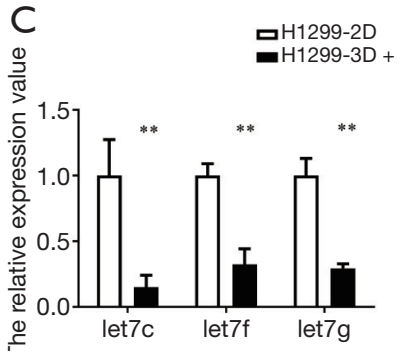

H520-3D + F

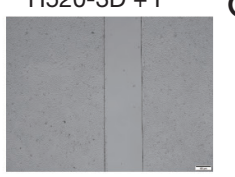

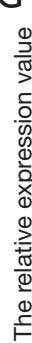

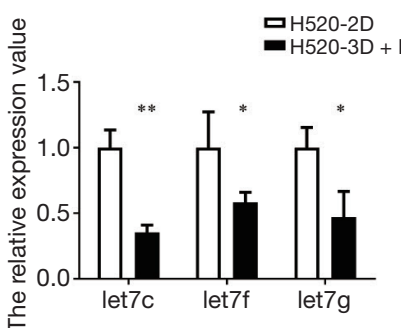

SK-MES-1-3D + F
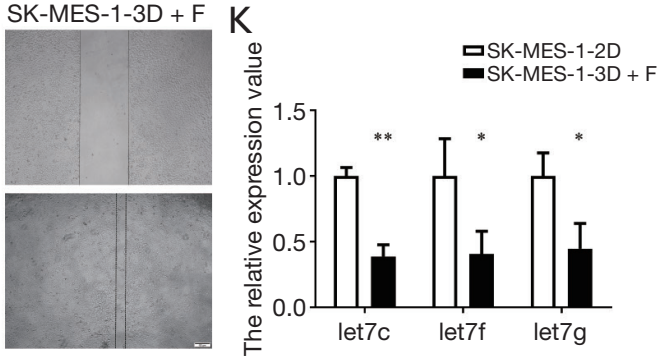
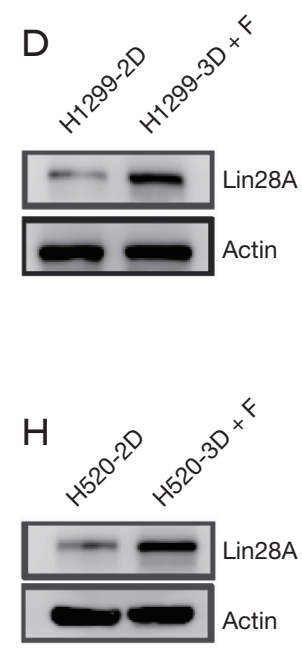

Figure 2 Lin28A/let-7c was expressed abnormally in lung cancer stem cells (LCSCs) from other lung cancer cell lines cultured in the 3-dimensional (3D) system. (A) Representative images of H1299-2D and H1299-3D+F cells from sphere formation assays (10x). (B) Representative images of H1299-2D and H1299-3D+F cells from wound healing assays (10x). (C) The realtime quantitative PCR (RT-qPCR) results of let-7c, let-7f, and let-7g in H1299-2D and H1299-3D+F cells. All of the results shown for the H1299-3D+F group are relative expression values in comparison with the H1299-2D group. (D) The western blot results of Lin28A and Lin28B in H1299-2D and H1299$3 \mathrm{D}+\mathrm{F}$ cells. (E) Representative images of H520-2D and H520-3D+F cells from sphere formation assays (10x). (F) Representative images of H520-2D and H520-3D+F cells from wound healing assays (10×). (G) RT-qPCR results of let-7 expression in H520-2D and H520-3D+F cells. (H) Western blot results of Lin28A and Lin28B expression in H520-2D and H520-3D+F cells. (I) Representative images of SK-MES1-2D and SK-MES-1-3D+F cells from sphere formation assays (10x). (J) Representative images of SK-MES-1-2D and SK-MES-1-3D+F cells from wound healing assays $(10 \times)$. (K) RT-qPCR results of let-7 expression in SK-MES-1-2D and SK-MES-1-3D+F cells. (L) Western blot results of Lin28A and Lin28B expression in SK-MES-1-2D and SK-MES-1-3D+F cells. * and ** indicates $\mathrm{P}<0.05$ and $\mathrm{P}<0.01$ between the groups, respectively.

(Figure 3G) (54). The analysis based on Lin28A expression in different cancer types showed the level of Lin28A in Stage 4 tissue samples to be markedly elevated compared to that in stage 1-3 tissue samples (Figure 3H) (54). Further, the TCGA survival analysis consistently evidenced a correlation between an increased level of Lin28A in lung cancer primary tissues and poor survival (Figure 3I) (55). Collectively, these results indicated that Lin28A/let-7c was dysregulated in LCSCs from lung cancer tissues and its abnormal expression was correlated with poor survival outcomes of LUAD.

\section{Let-7c inbibits the maintenance of LCSC properties via disruption of MAPK signaling patbway}

To probe the biological role of let-7c in LCSC enrichment and amplification, we induced let-7c over-expression in A549 cells, which were then cultured in the $3 \mathrm{D}+\mathrm{F}$ system 
A
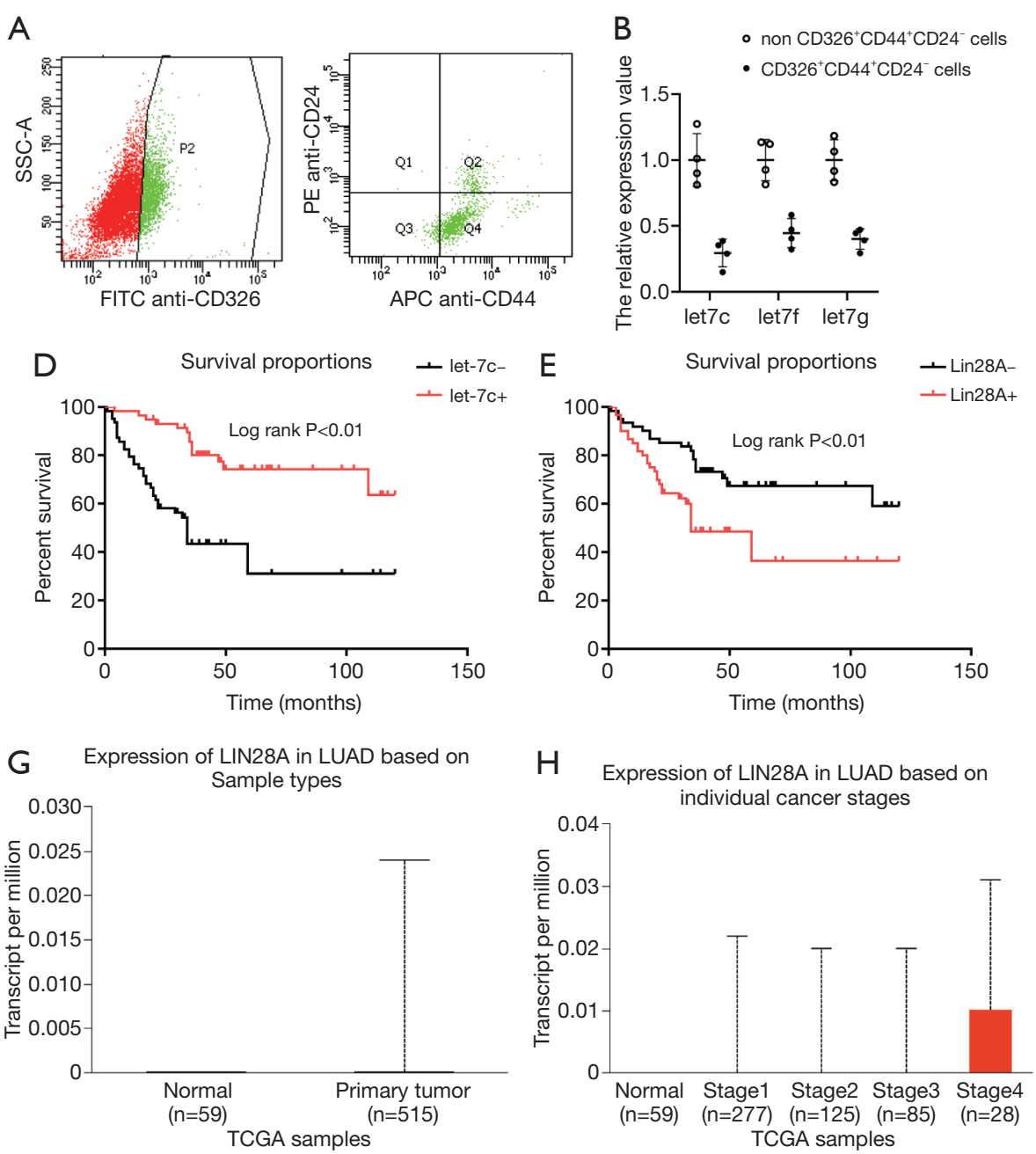
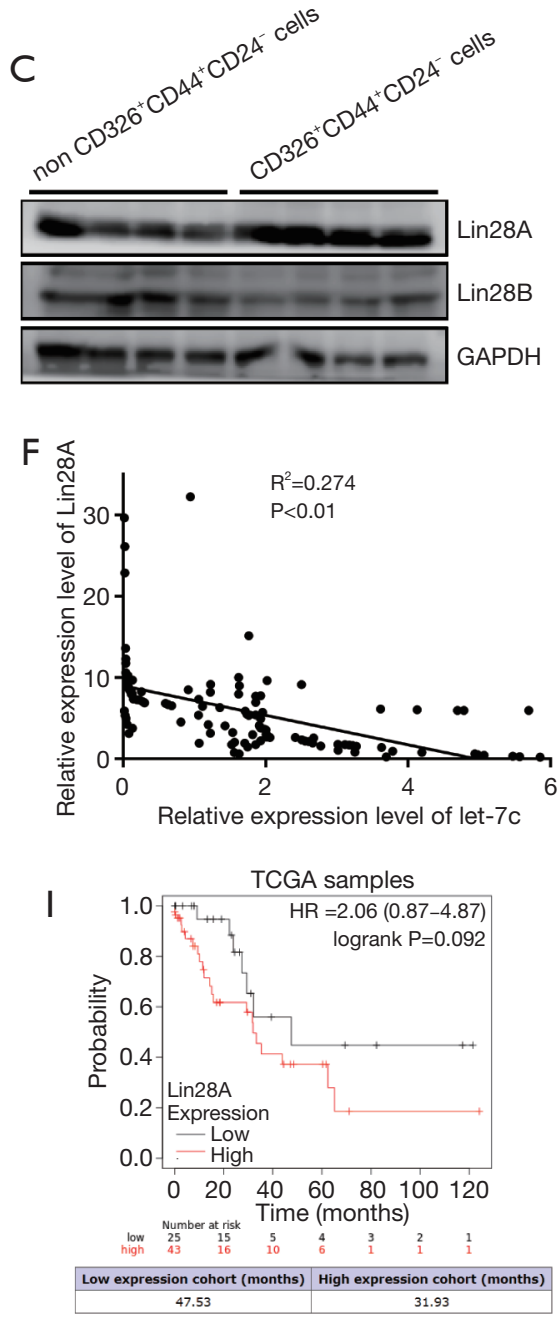

Figure 3 Lin28A/let-7c was dysregulated in lung cancer stem cells (LCSCs) from lung cancer tissues and its abnormal expression was correlated with poor survival outcomes. (A) Representative images of the flow cytometry analysis. CD $326^{+} \mathrm{CD} 44^{+} \mathrm{CD} 24^{-}$cells were isolated from lung adenocarcinoma (LUAD) tissues by flow sorting. (B) The realtime quantitative PCR (RT-qPCR) results of let-7c, let-7f, and let-7g expression in $\mathrm{CD} 326^{+} \mathrm{CD} 44^{+} \mathrm{CD} 24^{-}$cells and non-CD326 ${ }^{+} \mathrm{CD} 44^{+} \mathrm{CD} 24^{-}$cells from lung cancer samples. (C) Western blot results of Lin28A and Lin28B expression in the 2 groups. (D) Results of Kaplan-Meier analysis show a difference in the overall survival (OS) of let-

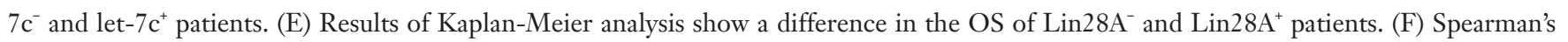
rank correlation result showed the negative correlation between let-7c and Lin28A expression in 125 clinical LUAD samples. (G) Results of TCGA data analysis show that Lin28A expression differs between normal tissues and LUAD tumor specimens. (H) Results of TCGA

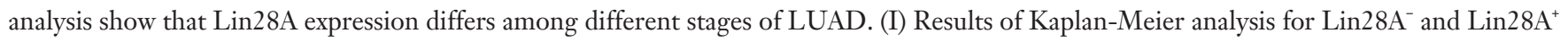
patients from the TCGA database.

$\left(\mathrm{A} 549^{\text {OV-let-7c }}-3 \mathrm{D}+\mathrm{F}\right)$. We examined the proportions of CD $326^{+} \mathrm{CD} 44^{+} \mathrm{CD} 24^{-}$cells in A549-2D, A549-3D, A549$3 \mathrm{D}+\mathrm{F}$, and $\mathrm{A} 549^{\text {OV-let-7c }}-3 \mathrm{D}+\mathrm{F}$ cells using flow cytometry. Consistent with our previous findings, an increase in the expression levels of CD326 was observed in A549-3D cells compared to A549-2D cells, and the increase was more dramatic in A549-3D+F cells (Figure 4A). However, fewer $\mathrm{CD} 326^{+}$cells were observed among the A549 ${ }^{\text {OV-let-7c }}-3 \mathrm{D}+\mathrm{F}$ cells compared to the A549-3D+F cells. Next, CD $326^{+}$ cells were gated, and the proportion of $\mathrm{CD} 44^{+} \mathrm{CD} 24^{-}$cells in the $\mathrm{CD} 326^{+}$population was analyzed. The proportion of $\mathrm{CD} 326^{+} \mathrm{CD} 44^{+} \mathrm{CD} 24^{-}$cells among A549-3D+F cells 
Table 1 Basic clinicopathological details of the study participants

\begin{tabular}{|c|c|}
\hline Clinicopathological parameter & No. of cases \\
\hline Total & 125 \\
\hline \multicolumn{2}{|l|}{ Sex } \\
\hline Male & 63 \\
\hline Female & 62 \\
\hline \multicolumn{2}{|l|}{ Age } \\
\hline$<60$ years & 61 \\
\hline$\geq 60$ years & 64 \\
\hline \multicolumn{2}{|l|}{ Stage } \\
\hline I & 38 \\
\hline II & 42 \\
\hline II-III & 19 \\
\hline III & 24 \\
\hline IV & 2 \\
\hline \multicolumn{2}{|l|}{ T stage } \\
\hline 1 & 14 \\
\hline 2 & 75 \\
\hline 3 & 30 \\
\hline 4 & 6 \\
\hline \multicolumn{2}{|l|}{$\mathrm{N}$ stage } \\
\hline 0 & 77 \\
\hline 1 & 37 \\
\hline 2 & 11 \\
\hline \multicolumn{2}{|l|}{ M stage } \\
\hline 0 & 123 \\
\hline 1 & 2 \\
\hline
\end{tabular}

was larger than that among A549-2D and A549-3D cells (Figure $4 A$ ). Moreover, fewer CD $326^{+} \mathrm{CD} 44^{+} \mathrm{CD} 24^{-}$cells were observed among A549 ${ }^{\text {OV-let-7c }}-3 \mathrm{D}+\mathrm{F}$ cells than among A549-3D+F cells, indicating that let $-7 \mathrm{c}$ inhibited the expression levels of LCSC phenotypic markers.

As LCSCs are considered to possess the characteristic of high self-renewal, we further compared the spheroid formation capacities of A549-2D, A549-3D, A549-3D+F, and $\mathrm{A} 549^{\text {OV-let-7c }}-3 \mathrm{D}+\mathrm{F}$ cells to examine the impact of let-7c on LCSC stemness in these cells. A549-3D+F cells formed larger and more numerous colonies compared to A5492D and A549-3D cells, but fewer and smaller cell colonies were detected in $\mathrm{A} 549^{\text {OV-let-7c }}-3 \mathrm{D}+\mathrm{F}$ cells compared to A549$3 \mathrm{D}+\mathrm{F}$ cells (Figure 4B). Next, RT-qPCR was performed for the detection of the mRNA expressions of classical stemness genes (Oct4, Sox2, Nanog, and Aldh1). Each gene showed significant up-regulation at the mRNA level in A549-3D+F cells in comparison with A549-2D and A549-3D cells, whereas significant mRNA down-regulation of the genes was observed in A549 ${ }^{\text {OV-let-7c }}-3 \mathrm{D}+\mathrm{F}$ cells in comparison with A549-3D+F cells (Figure 4C). These results indicated that $\mathrm{A} 549^{\text {OV-let-7c }}-3 \mathrm{D}+\mathrm{F}$ cells displayed significantly lower expression of phenotypic and genetic LCSC markers, suggesting that let-7c might be an inhibitor of LCSC enrichment and proliferation.

As LCSCs are considered to be more resistant to starvation-induced apoptosis and have more strong resistance to chemotherapy drugs $(52,56)$. Annexin- $\mathrm{V}$ apoptosis assay was then conducted to examine cell apoptosis among A549-2D, A549-3D, A549-3D+F, and A $549^{\text {OV-let-7c }}-3 \mathrm{D}+\mathrm{F}$ cells. The flow cytometry analysis showed less apoptotic cells in A549-3D+F compared to either A549-2D or A549-3D cells, but more apoptotic cells were detected in $\mathrm{A} 549^{\text {OV-let-7c }}-3 \mathrm{D}+\mathrm{F}$ compared to A549-3D+F cells (Figure 4D, Figure S2A). Further, the drug resistance assay showed although A549-3D+F were more resistant to cisplatin treatment, $\mathrm{A} 549^{\text {OV-let-7c }}-3 \mathrm{D}+\mathrm{F}$ were more sensitive to cisplatin treatment than A549-3D+F cells (Figure S2B).

Next, since LCSCs are considered to possess the characteristic of high migration and invasion abilities, we examined the migratory and invasive abilities of A5492D, A549-3D, A549-3D+F, and A549 ${ }^{\text {OV-let-7c }}-3 \mathrm{D}+\mathrm{F}$ cells by performing wound healing and Transwell invasion assays. After 48 hours, the wound closure rate of A549-3D+F cells was markedly increased compared to those of A549-2D and A549-3D cells (Figure 4E). With epithelial-mesenchymal transition (EMT) being the most critical cellular process in tumor invasion and spread (57), qPCR was carried out to detect the enriched transcription of biomarkers related to EMT. The expression of the epithelial cell biomarker E-cadherin, which is known for its conventional use, showed a decrease in A549-3D+F cells in comparison to A5492D and A549-3D cells, although the levels of $\mathrm{N}$-cadherin and $\beta$-catenin, which are well-documented mesenchymal biomarkers, and EMT-associated transcription factors (Snail, Slug, ZEB1, and Twist) displayed an increase. Meanwhile, the above-mentioned mesenchymal cell biomarkers were decreased significantly in A549 ${ }^{\text {OV-let-7c }}$ $3 \mathrm{D}+\mathrm{F}$ cells (Figure $4 F)$. Further, at 48 hours, the number of migratory cells observed to have crossed the Matrigel layer 


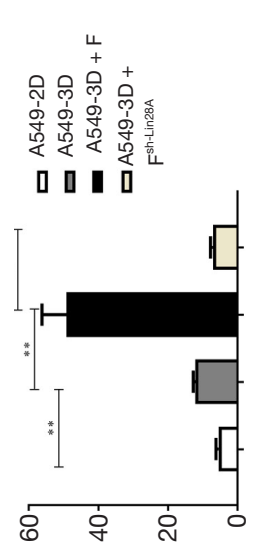

(\%) $\mathrm{s} \mid$ „ә $92 \varepsilon \square \supset$ to uoluodoud әบ।
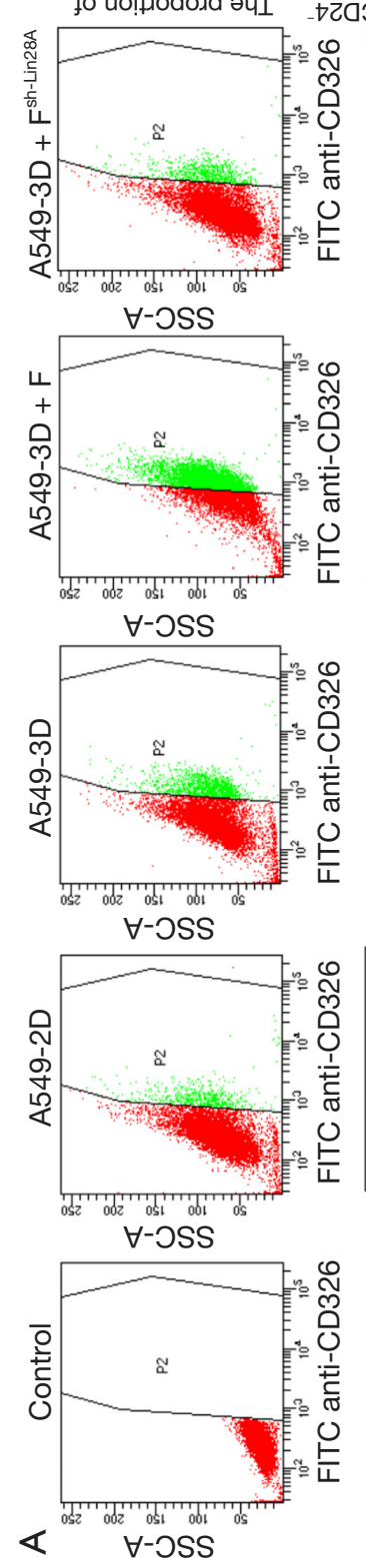

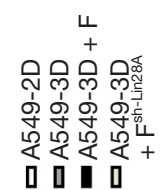

पा।

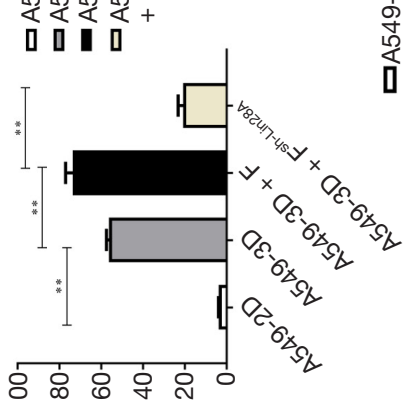

\%) uo!̣e|ndod

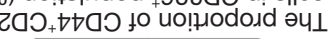

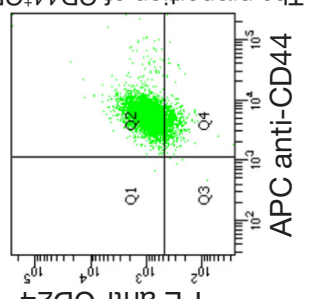

†२व०-I?ue $\exists d$

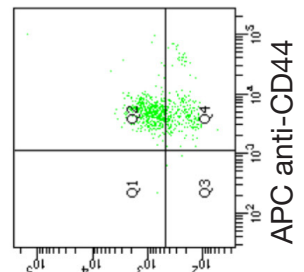

†टQว-!ฺUe $\exists d$

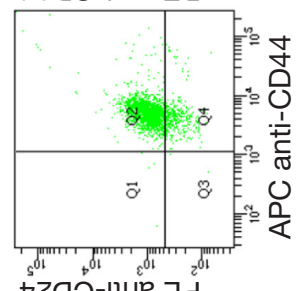

†ट०ว-!ฺue $\exists d$

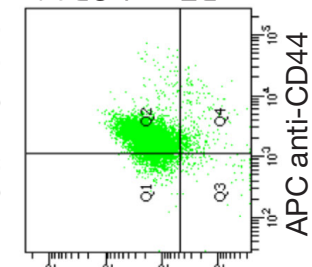

ดรดว-!?น์ $\exists d$

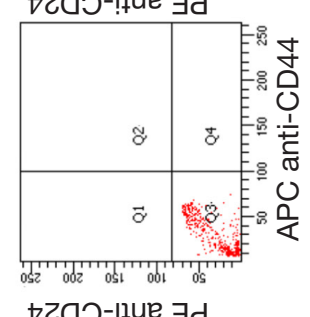

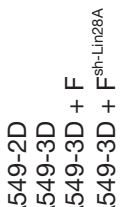

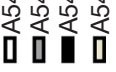

$: I: 工$

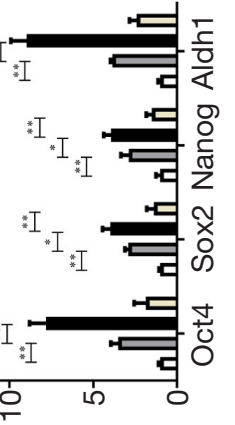

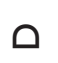

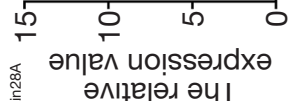

0

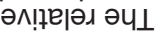

ลิติติ

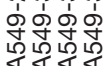

10.

1010

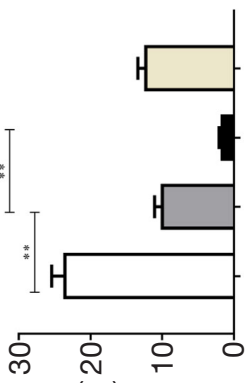

(\%) s॥әว

$\cup \quad$ ч

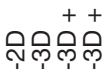

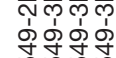
这造造造

प0口

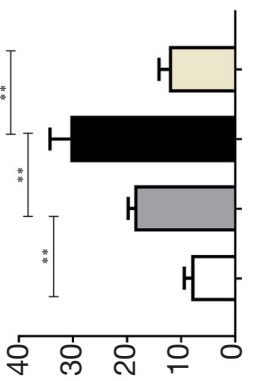

(\%) uo!̣emiot

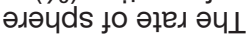
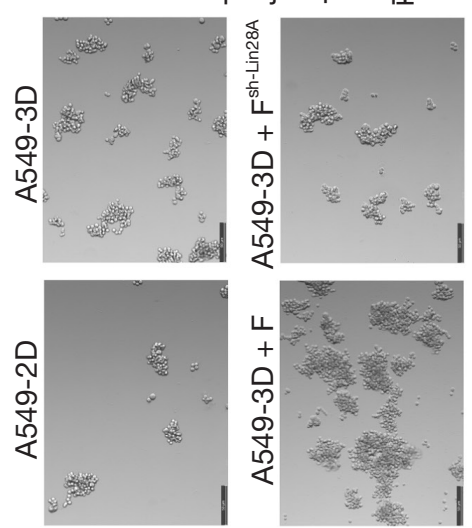

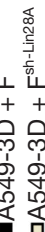

प10

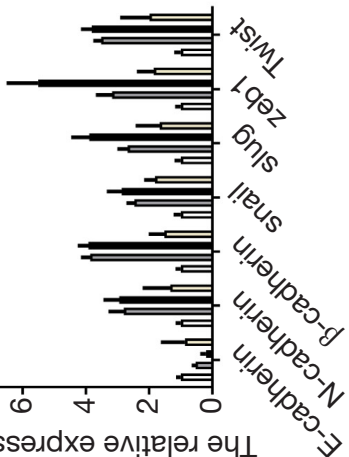

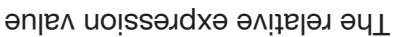

ш

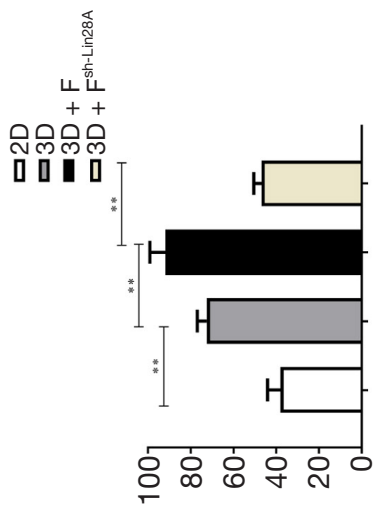

(\%) әреג ио!ฺелб!ाш әчц
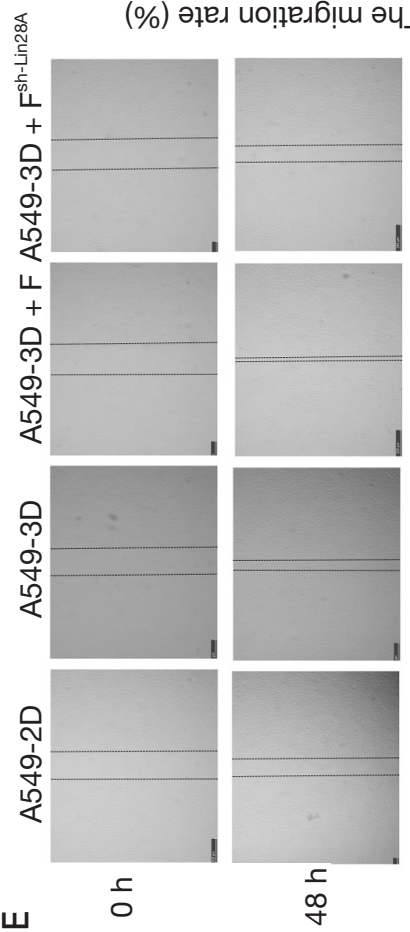


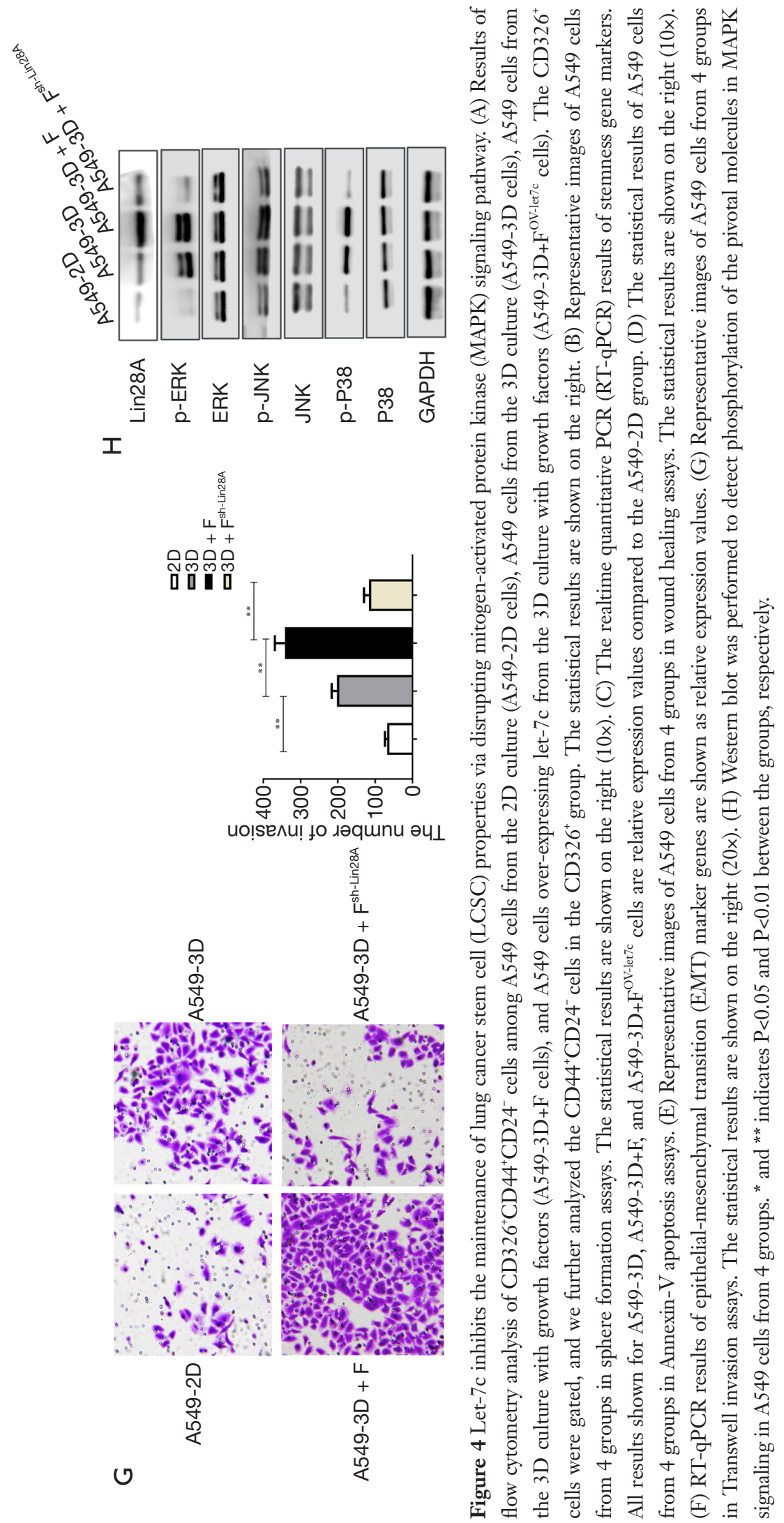


was elevated in the A549-3D+F group compared to in the A549-2D and A549-3D groups (Figure 4G). However, in the wound healing and Transwell invasion assays, we found that far fewer cells had migrated in the A549 ${ }^{\text {OV-let-7c }}-3 \mathrm{D}+\mathrm{F}$ group compared to those in the A549-3D+F group (Figure 4E, G). All of these results suggested that the elevated migration and invasion abilities of A549-3D+F cells were reversed by over-expressing let-7c.

Since our previous observations had indicated that $3 \mathrm{D}+\mathrm{F}$ culture had the effect of promoting LCSC amplification and stemness via MAPK signaling pathway (21), we then collected the supernatants of A549-2D, A549-3D, A549$3 \mathrm{D}+\mathrm{F}$, and $\mathrm{A} 549^{\mathrm{OV}-\mathrm{let}-7 \mathrm{c}}-3 \mathrm{D}+\mathrm{F}$ cells, after which we examined the levels of phosphorylated p38, c-Jun N-terminal kinase (JNK), and extracellular regulated protein kinases (ERK) via western blot. A549-3D and A549-3D+F cells exhibited up-regulation of the phosphorylation levels of these 3 major subunits of MAPK protein family in comparison with A549-2D cells; however, the phosphorylation levels were obviously down-regulated in $\mathrm{A} 549^{\text {OV-let-7c }}-3 \mathrm{D}+\mathrm{F}$ cells (Figure $4 H$ ), which implied that let-7c inhibited the maintenance of LCSC properties via disruption of MAPK signaling pathway.

\section{Lin28A plays an indispensable role in tumorigenesis and the promotion of LCSC expansion via MAPK signaling patbway}

Next, we transfected A549 cells with Lin28A short hairpin RNA (shRNA) and cultured them in the $3 \mathrm{D}+\mathrm{F}$ system $\left(\mathrm{A} 549^{\text {sh-Lin28A }}-3 \mathrm{D}+\mathrm{F}\right)$ to investigate the function of Lin28A in LCSC enrichment and proliferation. By flow cytometry analysis, fewer $\mathrm{CD} 326^{+}$cells and $\mathrm{CD} 326^{+} \mathrm{CD} 44^{+} \mathrm{CD} 24^{-}$cells were observed among A549 $9^{\text {sh-Lin2 } 28}-3 \mathrm{D}+\mathrm{F}$ cells than among A549-3D+F cells (Figure 5A), indicating Lin28A to be critical for the expression of phenotypic markers of LCSCs.

We further investigated the spheroid formation capacities of the cells, and observed the A549 $9^{\text {sh-Linn28A }}-3 \mathrm{D}+\mathrm{F}$ group to have fewer and smaller cell colonies than the A549-3D+F group (Figure 5B). Furthermore, we observed the A549 $9^{\text {sh-Lin28A }}-3 \mathrm{D}+\mathrm{F}$ group to have significant downregulation of Oct4, Sox2, Nanog, and Aldh1 at the mRNA level in comparison with the A549-3D+F group (Figure 5C). Annexin- $\mathrm{V}$ apoptosis assay showed more apoptotic cells in A $549^{\text {sh-Lin28A }}-3 \mathrm{D}+\mathrm{F}$ compared to A549-3D $+\mathrm{F}$ cells (Figure $5 D$, Figure $\mathrm{S} 2 \mathrm{C}$ ). And the drug resistance assay showed $\mathrm{A} 549^{\text {sh-Lin28A }}-3 \mathrm{D}+\mathrm{F}$ were less resistant to cisplatin treatment than A549-3D+F cells (Figure S2D). These results indicated that $\mathrm{A} 549^{\mathrm{sh}-\mathrm{Lin} 28 \mathrm{~A}}-3 \mathrm{D}+\mathrm{F}$ cells displayed significantly lower expression of LCSC phenotypic and genetic markers, even weakened the resistance to apoptosis and chemotherapy drugs, indicating that Lin28A is indispensable for the enrichment and proliferation of LCSCs.

The results of the wound healing assay showed the wound closure rate of A549 $9^{\text {sh-Lin28A }}-3 \mathrm{D}+\mathrm{F}$ cells was significantly lower than that of A549-3D+F cells after 48 hours (Figure $5 E$ ). The results of qPCR showed E-cadherin to be increased, but $\mathrm{N}$-cadherin, $\beta$-catenin, Snail, Slug, ZEB1, and Twist to be decreased in A549 ${ }^{\text {sh- }}$ Lin28A $-3 \mathrm{D}+\mathrm{F}$ cells in comparison with A549-3D+F cells (Figure 5F). Furthermore, the results of the Transwell invasion assay indicated that fewer A549 $9^{\text {sh-Lin28 }}-3 \mathrm{D}+\mathrm{F}$ cells than A549-3D+F cells had migrated across the Matrigel layer (Figure 5G). These results suggested that the elevated migration and invasion abilities of A549-3D+F cells were also dependent on Lin28A functions.

Then, we examined the levels of phosphorylated p38, JNK, and ERK in the supernatant of A549-2D, A549-3D, A549-3D+F, and A549 $9^{\text {sh-Lin28A }}-3 \mathrm{D}+\mathrm{F}$ cells, and observed that the phosphorylation levels were obviously down-regulated in the $\mathrm{A} 549^{\text {sh-Lin28A }}-3 \mathrm{D}+\mathrm{F}$ group (Figure $5 H$ ). The results above implied that Lin28A plays an indispensable role in tumorigenesis and promotes LCSC expansion via MAPK signaling pathway.

\section{Knockdown of Lin28A or over-expression of let-7c inbibited carcinogenesis and disrupted LCSC expansion in vivo}

Subsequently, we set out to examine the effect of Lin28A on oncogenesis in vivo. A xenograft model was established by administering non-obese diabetic/ severe combined immunodeficiency (NOD-SCID) mice with a subcutaneous injection of cells transfected with A549 $9^{\text {sh-Lin28A }}$ lentiviral constructs or their control cells. On day 24 after the injection, we observed a minimum 2-fold increase in the average tumor volumes in the A549 $9^{\text {sh-Lin28A }}$ group in comparison with the control (Figure 6A). We also investigated the roles of let-7c in tumorigenesis by injecting cells transduced with the A549 ${ }^{\text {OV-let-7c }}$ lentiviral constructs in a similar manner. Consistently, the growth rates of tumors in the A549 ${ }^{\text {OV-let-7c }}$ group far surpassed the rates in the $\mathrm{H} 520^{\text {OV-CTRL }}$ group (Figure 6 B).

Additionally, the RNA levels of let-7c and protein levels of Lin28A in xenografts were examined. As expected, the qPCR analysis demonstrated that the transcription of let-7c was elevated in both the A549 $9^{\text {sh-Lin28A }}$ and A549 ${ }^{\text {OV-let-7c }}$ groups 

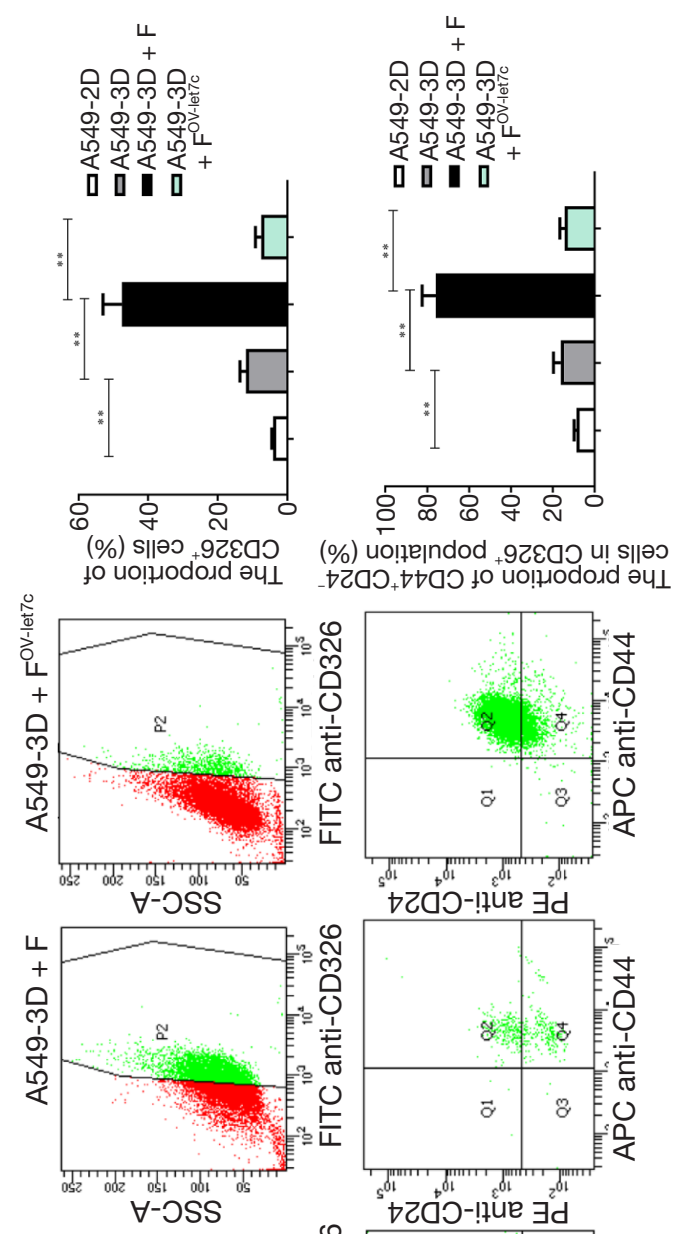

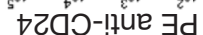
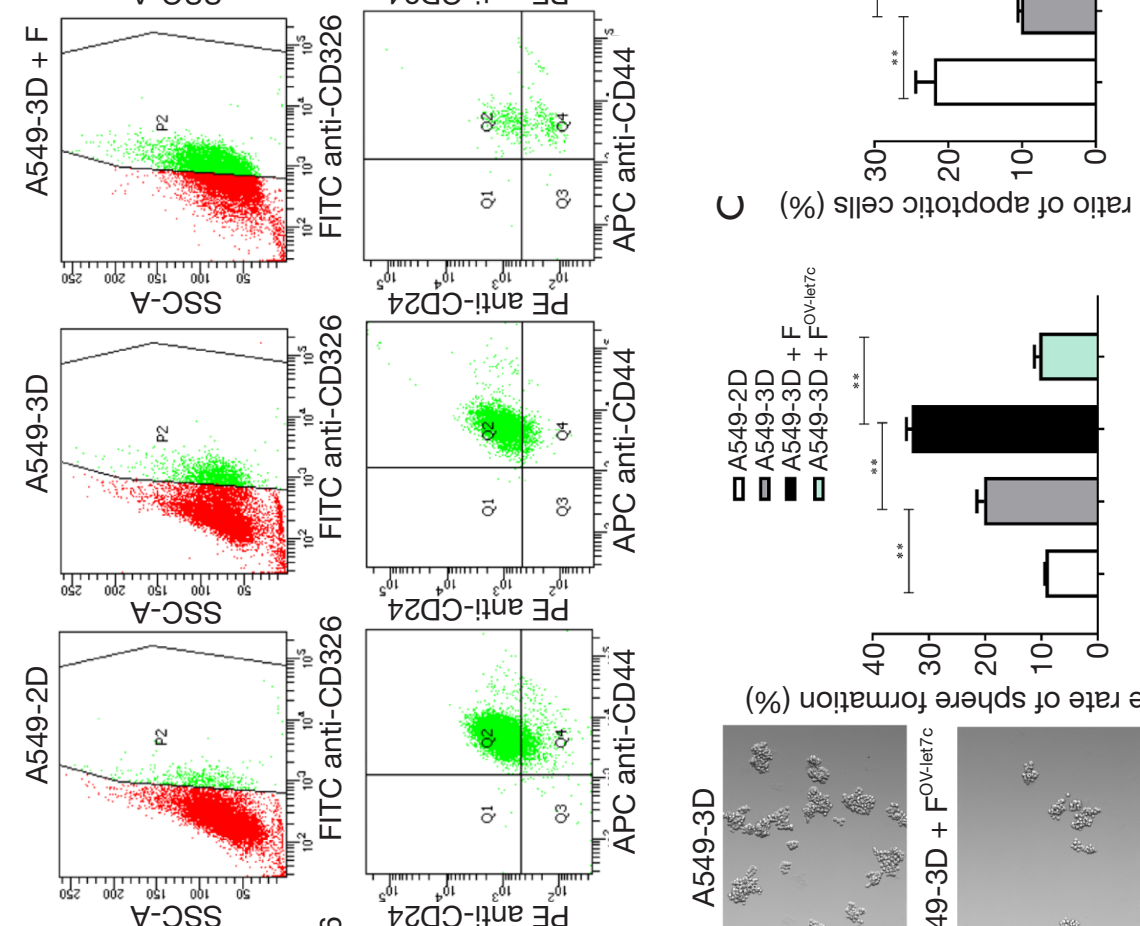

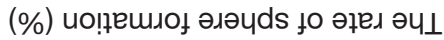

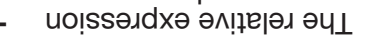
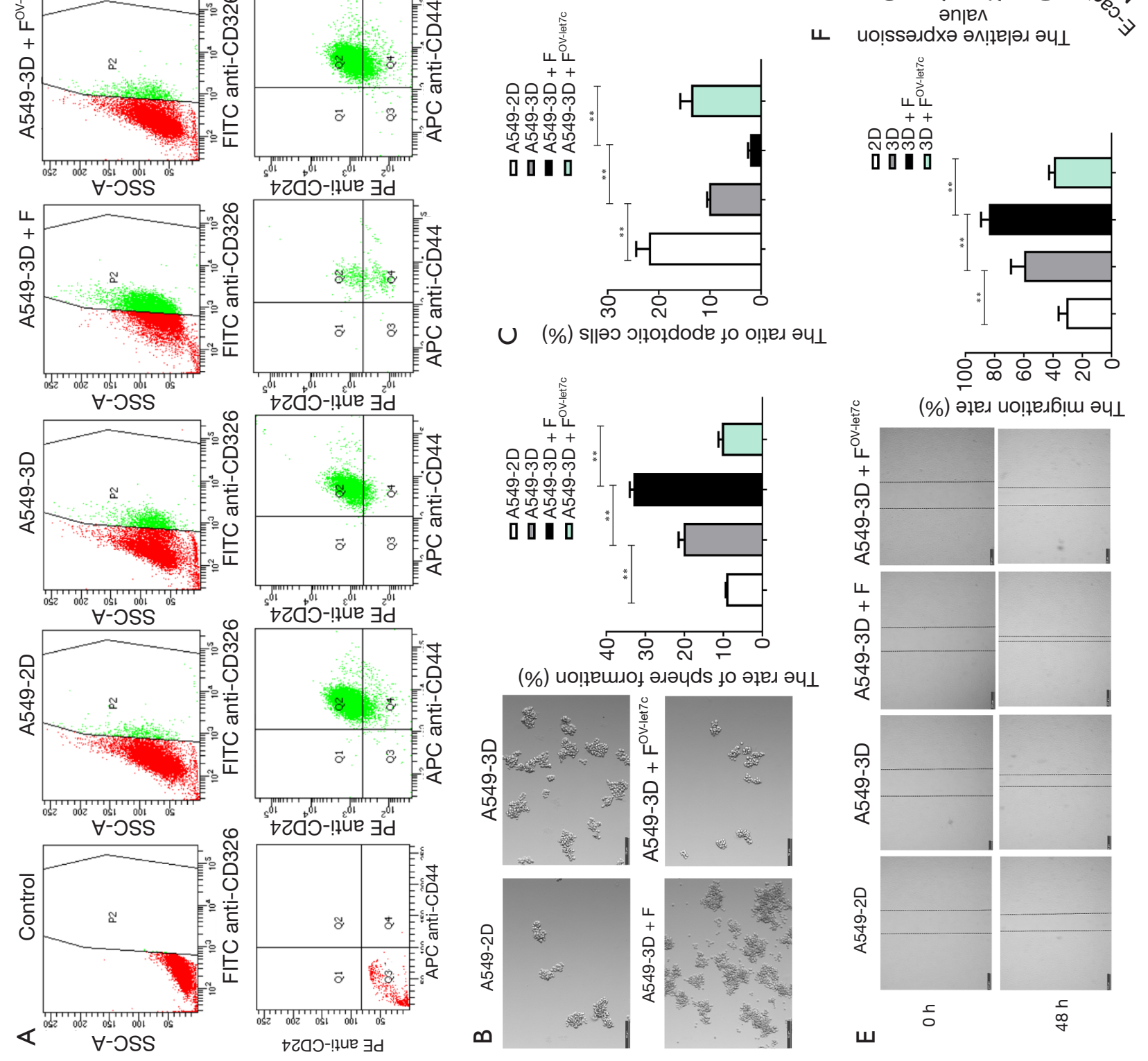


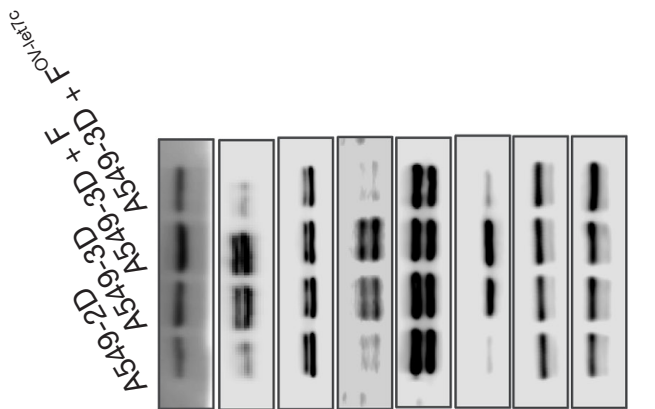$$
\text { . }
$$

I

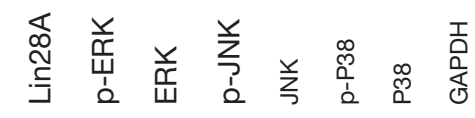
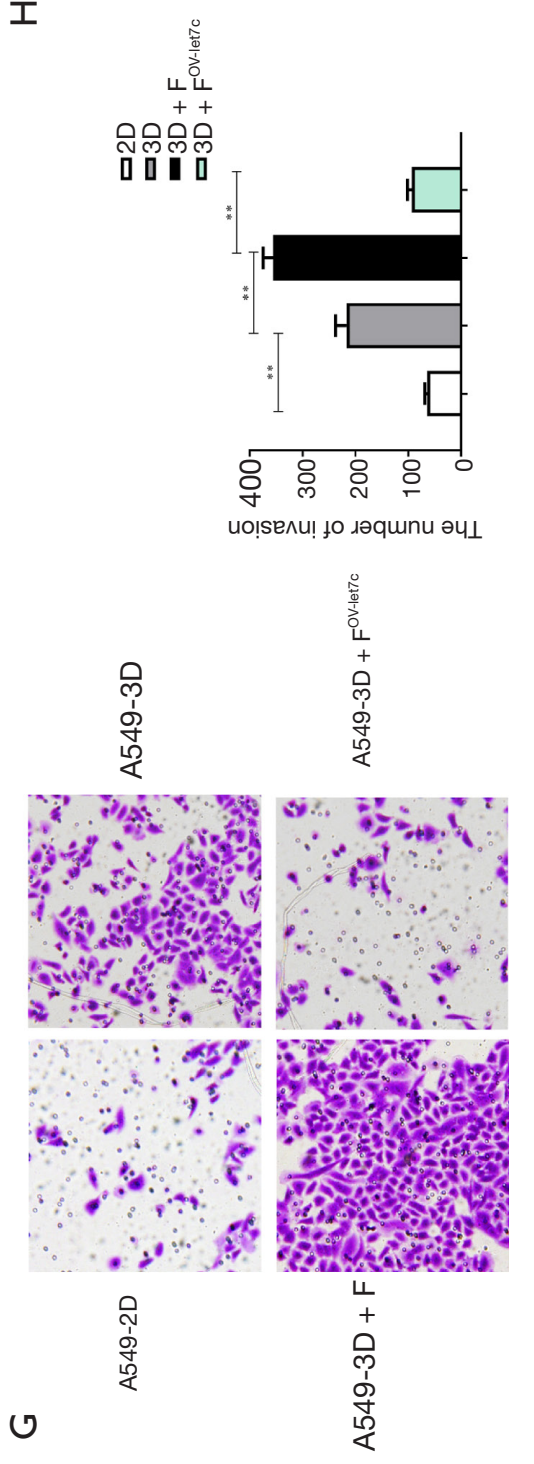

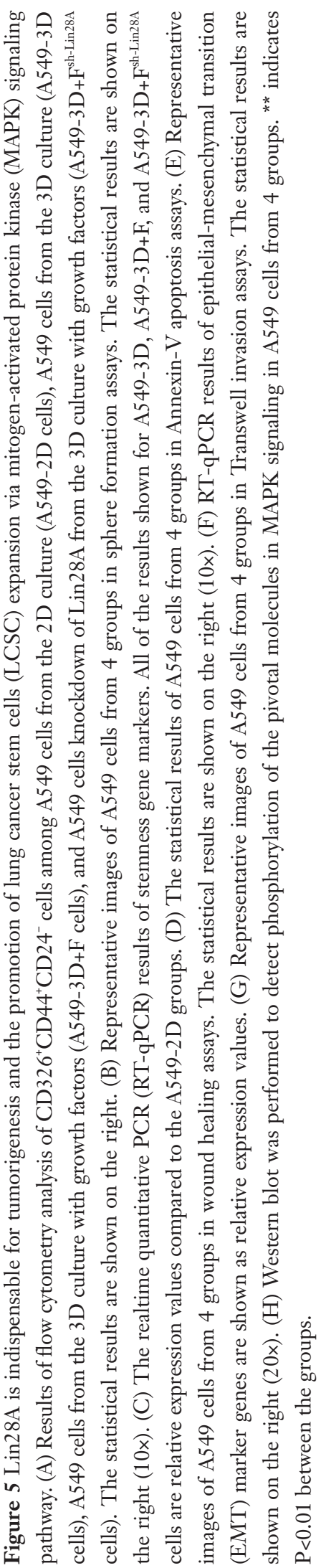



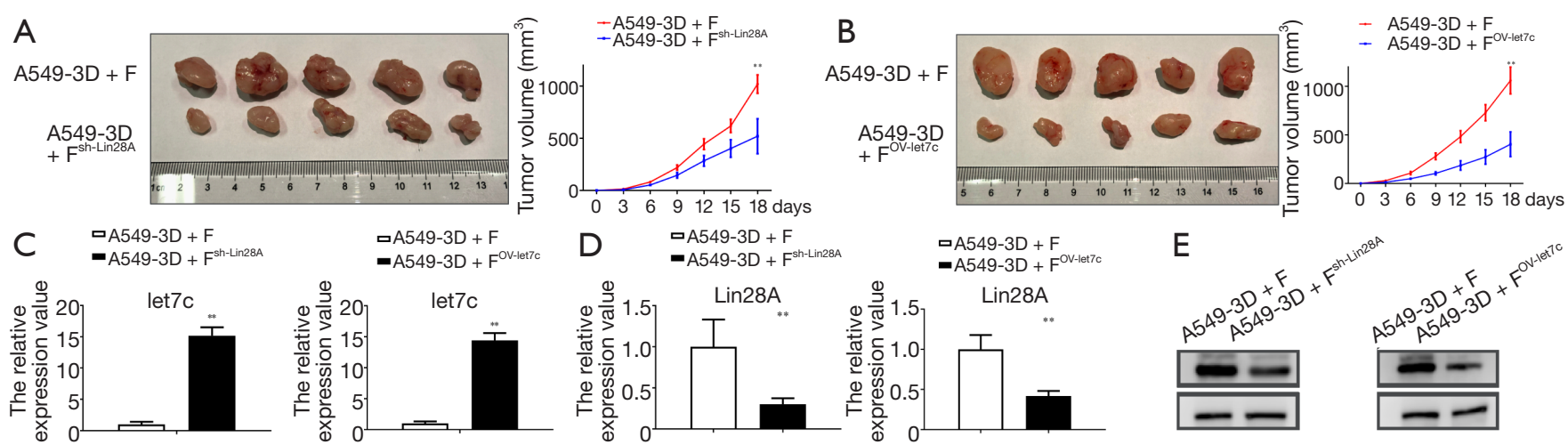
$=\mathrm{A} 549-3 \mathrm{D}+\mathrm{F}^{\mathrm{OV}-\mathrm{let} / \mathrm{C}}$
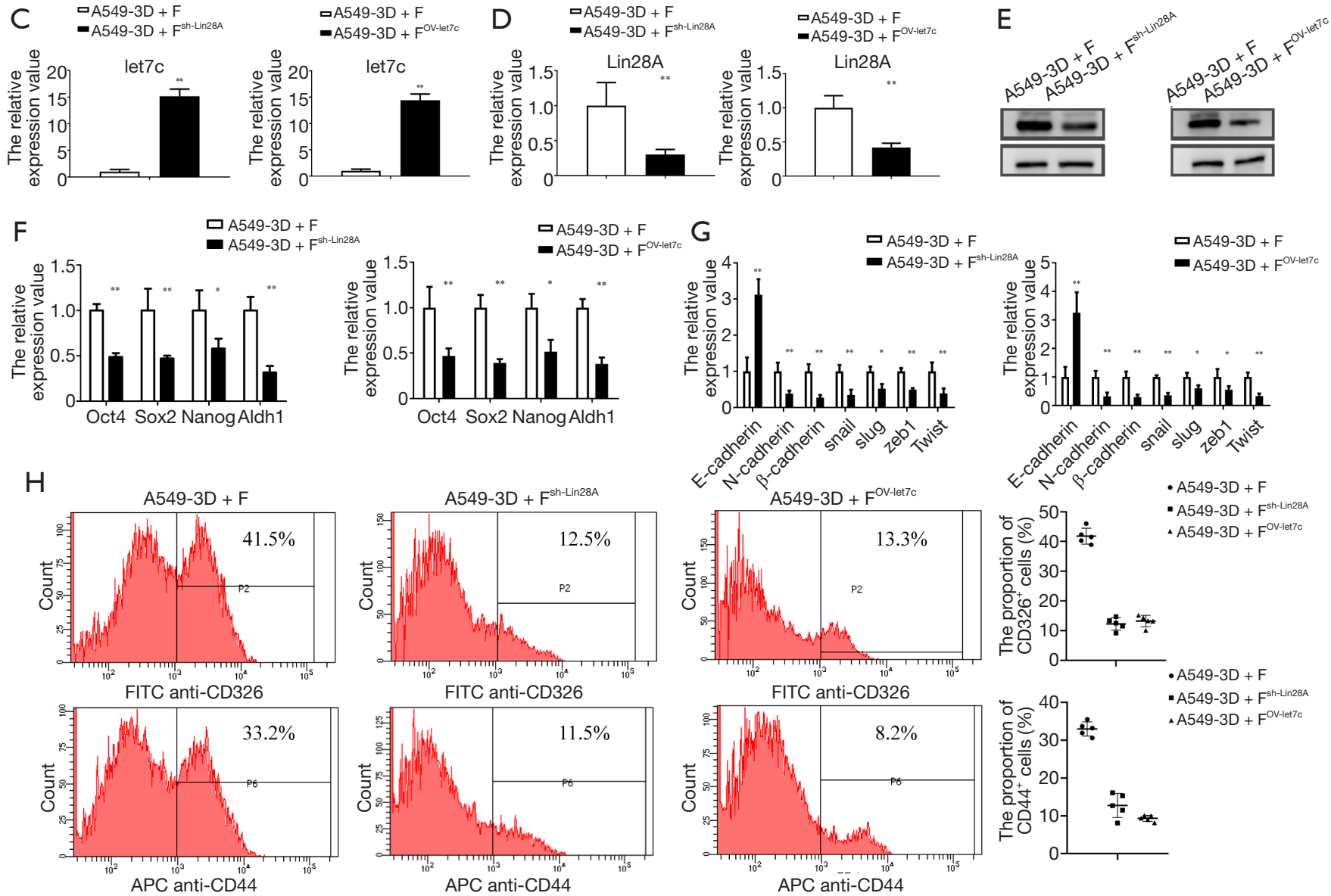

Figure 6 Knockdown of Lin28A or over-expression of let-7c inhibited carcinogenesis and disrupted lung cancer stem cell (LCSC) expansion in vivo. (A) NOD-SCID mice were subcutaneously injected with A549 cells from the 3D culture with growth factors (A549-3D+F cells) and A549 cells knockdown of Lin28A from the 3D culture with growth factors (A549-3D+ $\mathrm{F}^{\mathrm{sh}-\mathrm{Lin} 28 \mathrm{~A}}$ cells). The size of the tumors formed is shown at various time points after injection. (B) NOD-SCID mice were subcutaneously injected with A549-3D+F and A549 cells over-expressing let-7c from the 3D culture with growth factors ( $\mathrm{A} 549-3 \mathrm{D}+\mathrm{F}^{\text {OV-let7 }}$ cells). The size of the tumors formed is shown at various time points after injection. (C) The realtime quantitative PCR (RT-qPCR) results of let-7c expression in A549-3D+F, A549-3D+F $\mathrm{F}^{\text {sh-Lin28A }}$, and A549-3D+F ${ }^{\text {OV- }}$ ${ }^{l e t 7}$ mice. All the results shown for the A549-3D+F $\mathrm{F}^{\text {sh-Lin28A }}$ and A549-3D+F $\mathrm{F}^{\text {OV-let7 }}$ groups are relative expression values compared to the A549$3 \mathrm{D}+\mathrm{F}$ group. (D) RT-qPCR results of Lin28A expression in 3 groups. (E) Western blot was carried out to detect Lin28A expression in 3 groups. (F) RT-qPCR results of stemness gene markers in 3 groups. (G) RT-qPCR results of EMT marker genes are shown as relative expression values. $(\mathrm{H})$ Results of flow cytometry analysis of $\mathrm{CD} 326^{+}$and $\mathrm{CD} 44^{+}$cells from 3 groups. The statistical results are shown on the right. * and ${ }^{* *}$ indicates $\mathrm{P}<0.05$ and $\mathrm{P}<0.01$ between the groups, respectively. 
compared with their respective controls (Figure 6C). The qPCR and western blot results showed down-regulation of Lin28A in the A549 ${ }^{\text {sh-Lin28A }}$ and A549 ${ }^{\text {OV-let-7c }}$ groups (Figure $6 D, E)$, as well as reduced mRNA levels of Oct4, Sox2, Nanog, and Aldh1 in the A549 ${ }^{\text {sh-Lin28A }}$ and A549 ${ }^{\text {OV-let-7c }}$ groups (Figure $6 F$ ). Similarly, the mRNA levels of E-cadherin were reduced, while those of $\mathrm{N}$-cadherin, $\beta$-catenin, Snail, Slug, ZEB1, and Twist1 exhibited an increase (Figure 6G).

We further extracted the tumor tissues from the mice and analyzed the proportions of CSCs by flow cytometry. Markedly fewer CD $326^{+}$and CD $44^{+}$cells were observed in A549 ${ }^{\text {sh-Lin28A }}$ and A549 $9^{\text {OV-let-7c }}$ mice compared to A549 group (Figure 6H). All of these results implied that knockdown of Lin28A or over-expression of let-7c could inhibit carcinogenesis and disrupt LCSC expansion in vivo.

\section{Discussion}

The dysregulation of miRNA expression is related to and is functionally important in many diseases, including cancer $(23,28)$. Among all tumor-suppressing miRNAs, a decrease in let-7 is highly common in tumors and is usually associated with a poor prognostic outcome $(36,58,59)$. Functionally, the reduction of let-7 miRNAs leads to overexpression of their carcinogenic targets, such as resistance to audiogenic seizures (RAS), MYC proto-oncogene (MYC), and high mobility group AT-hook 2 (HMGA2) (60-62). Furthermore, in many cancers and embryonic stem cells, although the primary transcripts of let-7 are still actively transcribed, mature let- 7 is not produced as expected, due to the 2 highly conserved RNA-binding proteins Lin28A and Lin28B directly bind to pre-let-7 or pri-let-7 to inhibit the biogenesis of mature let-7 miRNAs (36). In particular, binding of Lin28A/B to the terminal loop of the precursor let-7 results in the recruitment of the terminal uridylyl transferase ZCCHC11, which polyuridylates pre-let-7, thus blocking miRNA biogenesis and tumor-suppressing functions (36). Lin28A/B blocks the expression of let-7, which negatively regulates Lin28A/B levels through its binding to the 3'UTR of Lin $28 \mathrm{~A} / \mathrm{B}$ mRNA; through this, a dual negative feedback loop is established (63).

Lin28A has been shown as a stem cell pluripotency factor (51). Treatment of adult fibroblasts with Oct4, Sox2, Nanog and Lin28A allowed for their successful reprogramming to induced pluripotent stem cells (PSCs) (64). The up-regulation and activation of Lin28A/ $\mathrm{B}$ is a hallmark of in multiple malignancies, including glioblastoma, and cancers of the ovaries, stomach, prostate, and breast $(34,35)$. Although the functions and mechanisms of the double-negative feedback loop of Lin28/ let-7 in CSCs have been elucidated in many cancers, the relationship and role of Lin28/let-7 in LCSCs are still not well elucidated.

In this study, we detected that the levels of let7 miRNAs, and found that, in particular, let-7c was significantly down-regulated in LCSCs amplified in our $3 \mathrm{D}$ culture system. Let-7c is a member of the let-7 family which is commonly known as a putative tumor suppressor of several cancer cell lines $(37,38,40)$, but is also reported to play an important dual role in regulating the tumorigenic and metastatic abilities of cancer cells (45). Further, let-7c can target several genes, such as homeobox A1 (HOXA1), integrin subunit beta 3 (ITGB3), mitogen-activated protein kinase kinase kinase kinase 3 (MAP4K3), and tribbles pseudokinase 2 (TRIB2), to inhibit non-small cell lung cancer proliferation, migration, and tumorigenesis (65-67). Regarding its roles in regulating stem cells, let-7c has been identified to significantly abolish symmetric division of stem cells by inhibiting Wnt signaling (68).

However, there is no direct evidence of the relationship between let-7c and Lin28A/B in lung cancer. Our search for let-7c target genes on TargetScan showed that Lin28B was among the top 10 genes. Unexpectedly, the transcription and protein levels of Lin28B showed no difference between LCSCs and non-LCSCs, whereas the expression of Lin28A was significantly up-regulated in LCSCs amplified in our 3D culture system. The results indicated that although $\operatorname{Lin} 28 \mathrm{~A}$ and $\operatorname{Lin} 28 \mathrm{~B}$ have both been reported to play roles in the progression of lung cancer, Lin28A appeared to be more important to the enrichment and amplification of LCSCs.

The abnormal expression of Lin28A/let-7c was not only detected in LCSCs from A549 cells, but also in LCSCs from other lung cancer cell lines, including LUAD and LUSC cell lines. We also uncovered that Lin28A/let-7c was dysregulated in LCSCs obtained from lung cancer tissues. Furthermore, the abnormal expression of Lin28A/let$7 \mathrm{c}$ was correlated with poor survival outcomes in patients from our cohort and the TCGA database. Let-7c overexpression or inhibition of Lin28A suppressed stem cell self-renewal and carcinogenesis, and reduced the proportion of undifferentiated cells. All of these data imply that Lin28A and let-7c, but not Lin28B or other let-7 miRNAs, might play vital roles in the development of LCSCs in different subtypes of lung cancer.

Hedgehog, Wnt, and Notch are the canonical 
signaling pathways involved in mediating various stem cell characteristics, such as self-renewal, cell fate decisions, survival, proliferation, and differentiation $(69,70)$. However, in our previous studies, we demonstrated that the growth factors promoting LCSC amplification and stemness mainly depended on MAPK signaling pathway (21). Lin28A/let7c was also found to regulate the properties of LCSCs via MAPK signaling pathway. Ras genes are regulated by let7 miRNAs due to the 3'-UTRs of these genes containing let-7 complementary sites (60). Deletion of let-7c has been reported to promote the activation of the JNK and P38 MAPK pathways in mesenchymal stem cells (41). Tsanov et al. found that Lin28A was phosphorylated by MAPK/ERK in PSCs, which increased its levels via post-translational stabilization (71). Our findings inversely indicated that MAPK signaling was the downstream pathway of Lin28A.

In this study, we have established an efficient 3D culture method for the amplification of different subtypes of LCSCs, with the intention of overcoming the challenges faced in the purification and amplification of LCSCs which limit large-scale clinical treatment targeting LCSCs. We have also illuminated the molecular mechanisms of Lin28A/let-7c/MAPK signaling pathway involved in the proliferation and development of LCSCs, even defining an axis that connects the gene, miRNA, signaling pathway, and stem cell properties. This pathway might be a potential therapeutic target for reducing and even eliminating LCSCs in clinical research in the future.

\section{Acknowledgments}

Funding: This work was supported by the National Natural Science Foundation of China (grant No. 82072588, 81702280 , and 81872143), the National Science and Technology Support Program of China (grant No. 2018ZX09201015), the National Key Research and Development Program of China: The Net construction of human genetic resource Bio-bank in North China (grant No. 2016YFC1201703), the Project of Science and Technology of Tianjin (grant No. 18JCQNJC82700), and the Key Project of Tianjin Health and Family Planning Commission (grant No. 16KG126).

\section{Footnote}

Reporting Checklist: The authors have completed the ARRIVE reporting checklist. Available at https://dx.doi. org/10.21037/atm-21-2124
Data Sharing Statement: Available at https://dx.doi. org/10.21037/atm-21-2124

Conflicts of Interest: All authors have completed the ICMJE uniform disclosure form (available at https://dx.doi. org/10.21037/atm-21-2124). The authors have no conflicts of interest to declare.

Ethical Statement: The authors are accountable for all aspects of the work in ensuring that questions related to the accuracy or integrity of any part of the work are appropriately investigated and resolved. This study was approved by the Ethics Committee of Tianjin Medical University (Approved No.: Ek2017055). All experiments were performed in accordance with the principles of the Declaration of Helsinki (as revised in 2013) and written consent was obtained from all patients. All procedures involving animals were approved by the Ethics Committee for Animal Experiments at the Tianjin Medical University Cancer Hospital and Institute (Approved No.: NSFCAE-2020101) and were performed in accordance with the Guide for the Care and Use of Laboratory Animals.

Open Access Statement: This is an Open Access article distributed in accordance with the Creative Commons Attribution-NonCommercial-NoDerivs 4.0 International License (CC BY-NC-ND 4.0), which permits the noncommercial replication and distribution of the article with the strict proviso that no changes or edits are made and the original work is properly cited (including links to both the formal publication through the relevant DOI and the license). See: https://creativecommons.org/licenses/by-nc-nd/4.0/.

\section{References}

1. Siegel RL, Miller KD, Jemal A. Cancer statistics, 2020. CA Cancer J Clin 2020;70:7-30.

2. Yang CY, Yang JC, Yang PC. Precision Management of Advanced Non-Small Cell Lung Cancer. Annu Rev Med 2020;71:117-36.

3. Gridelli C, Rossi A, Carbone DP, et al. Non-small-cell lung cancer. Nat Rev Dis Primers 2015;1:15009.

4. Kim C, Giaccone G. Precision oncology in non-small-cell lung cancer: opportunities and challenges. Nat Rev Clin Oncol 2018;15:348-9.

5. Planchard D, Popat S, Kerr K, et al. Metastatic non-small cell lung cancer: ESMO Clinical Practice Guidelines for diagnosis, treatment and follow-up. Ann Oncol 
2018;29:iv192-237.

6. Greten FR. Cancer: Tumour stem-cell surprises. Nature 2017;543:626-7.

7. Batlle E, Clevers H. Cancer stem cells revisited. Nat Med 2017;23:1124-34.

8. Beck B, Blanpain C. Unravelling cancer stem cell potential. Nat Rev Cancer 2013;13:727-38.

9. Koren A, Motaln H, Cufer T. Lung cancer stem cells: a biological and clinical perspective. Cell Oncol (Dordr) 2013;36:265-75.

10. Moharil RB, Dive A, Khandekar S, et al. Cancer stem cells: An insight. J Oral Maxillofac Pathol 2017;21:463.

11. MacDonagh L, Gray SG, Breen E, et al. Lung cancer stem cells: The root of resistance. Cancer Lett 2016;372:147-56.

12. Najafi M, Farhood B, Mortezaee K. Cancer stem cells (CSCs) in cancer progression and therapy. J Cell Physiol 2019;234:8381-95.

13. Heng WS, Gosens R, Kruyt FAE. Lung cancer stem cells: origin, features, maintenance mechanisms and therapeutic targeting. Biochem Pharmacol 2019;160:121-33.

14. Atashzar MR, Baharlou R, Karami J, et al. Cancer stem cells: A review from origin to therapeutic implications. J Cell Physiol 2020;235:790-803.

15. Ayob AZ, Ramasamy TS. Cancer stem cells as key drivers of tumour progression. J Biomed Sci 2018;25:20.

16. Bajaj J, Diaz E, Reya T. Stem cells in cancer initiation and progression. J Cell Biol 2020;219:e201911053.

17. Sreepadmanabh M, Toley BJ. Investigations into the cancer stem cell niche using in-vitro 3-D tumor models and microfluidics. Biotechnol Adv 2018;36:1094-110.

18. Pereira LP, Silva P, Duarte M, et al. Targeting Colorectal Cancer Proliferation, Stemness and Metastatic Potential Using Brassicaceae Extracts Enriched in Isothiocyanates: A 3D Cell Model-Based Study. Nutrients 2017;9:368.

19. Bielecka ZF, Maliszewska-Olejniczak K, Safir IJ, et al. Three-dimensional cell culture model utilization in cancer stem cell research. Biol Rev Camb Philos Soc 2017;92:1505-20.

20. Paolillo M, Colombo R, Serra M, et al. Stem-Like Cancer Cells in a Dynamic 3D Culture System: A Model to Study Metastatic Cell Adhesion and Anti-Cancer Drugs. Cells 2019;8:1434.

21. Liu P, Zhang R, Yu W, et al. FGF1 and IGF1conditioned $3 \mathrm{D}$ culture system promoted the amplification and cancer stemness of lung cancer cells. Biomaterials 2017;149:63-76.

22. Cheng CJ, Bahal R, Babar IA, et al. MicroRNA silencing for cancer therapy targeted to the tumour microenvironment. Nature 2015;518:107-10.

23. Rusek AM, Abba M, Eljaszewicz A, et al. MicroRNA modulators of epigenetic regulation, the tumor microenvironment and the immune system in lung cancer. Mol Cancer 2015;14:34.

24. Khan AQ, Ahmed EI, Elareer NR, et al. Role of miRNARegulated Cancer Stem Cells in the Pathogenesis of Human Malignancies. Cells 2019;8:840.

25. Agliano A, Calvo A, Box C. The challenge of targeting cancer stem cells to halt metastasis. Semin Cancer Biol 2017;44:25-42.

26. Lin S, Gregory RI. MicroRNA biogenesis pathways in cancer. Nat Rev Cancer 2015;15:321-33.

27. Yan H, Bu P. Non-coding RNAs in cancer stem cells. Cancer Lett 2018;421:121-6.

28. Xue J, Yang J, Luo M, et al. MicroRNA-targeted therapeutics for lung cancer treatment. Expert Opin Drug Discov 2017;12:141-57.

29. Garofalo M, Croce CM. Role of microRNAs in maintaining cancer stem cells. Adv Drug Deliv Rev 2015;81:53-61.

30. Van Roosbroeck K, Fanini F, Setoyama T, et al. Combining Anti-Mir-155 with Chemotherapy for the Treatment of Lung Cancers. Clin Cancer Res 2017;23:2891-904.

31. Jeong K, Yu YJ, You JY, et al. Exosome-mediated microRNA-497 delivery for anti-cancer therapy in a microfluidic 3D lung cancer model. Lab Chip 2020;20:548-57.

32. Lee J, Choi KJ, Moon SU, et al. Theragnosis-based combined cancer therapy using doxorubicin-conjugated microRNA-221 molecular beacon. Biomaterials 2016;74:109-18.

33. Boca S, Gulei D, Zimta AA, et al. Nanoscale delivery systems for microRNAs in cancer therapy. Cell Mol Life Sci 2020;77:1059-86.

34. Carmel-Gross I, Bollag N, Armon L, et al. LIN28: A Stem Cell Factor with a Key Role in Pediatric Tumor Formation. Stem Cells Dev 2016;25:367-77.

35. Wang T, Wang G, Hao D, et al. Aberrant regulation of the LIN28A/LIN28B and let-7 loop in human malignant tumors and its effects on the hallmarks of cancer. Mol Cancer 2015;14:125.

36. Balzeau J, Menezes MR, Cao S, et al. The LIN28/let-7 Pathway in Cancer. Front Genet 2017;8:31.

37. Mulholland EJ, Green WP, Buckley NE, et al. Exploring the Potential of MicroRNA Let-7c as a Therapeutic for Prostate Cancer. Mol Ther Nucleic Acids 2019;18:927-37. 
38. Tang H, Ma M, Dai J, et al. miR-let-7b and miR-let-7c suppress tumourigenesis of human mucosal melanoma and enhance the sensitivity to chemotherapy. J Exp Clin Cancer Res 2019;38:212.

39. Jilek JL, Zhang QY, Tu MJ, et al. Bioengineered Let7c Inhibits Orthotopic Hepatocellular Carcinoma and Improves Overall Survival with Minimal Immunogenicity. Mol Ther Nucleic Acids 2019;14:498-508.

40. Huang M, Gong X. Let-7c Inhibits the Proliferation, Invasion, and Migration of Glioma Cells via Targeting E2F5. Oncol Res 2018;26:1103-11.

41. Liu GX, Ma S, Li Y, et al. Hsa-let-7c controls the committed differentiation of IGF-1-treated mesenchymal stem cells derived from dental pulps by targeting IGF-1R via the MAPK pathways. Exp Mol Med 2018;50:1-14.

42. Fu X, Mao X, Wang Y, et al. Let-7c-5p inhibits cell proliferation and induces cell apoptosis by targeting ERCC6 in breast cancer. Oncol Rep 2017;38:1851-6.

43. Guo Y, Li S, Qu J, et al. Let-7c inhibits metastatic ability of mouse hepatocarcinoma cells via targeting mannoside acetylglucosaminyltransferase 4 isoenzyme A. Int J Biochem Cell Biol 2014;53:1-8.

44. Sun D, Layer R, Mueller AC, et al. Regulation of several androgen-induced genes through the repression of the miR-99a/let-7c/miR-125b-2 miRNA cluster in prostate cancer cells. Oncogene 2014;33:1448-57.

45. Xie Y, Zhang H, Guo XJ, et al. Let-7c inhibits cholangiocarcinoma growth but promotes tumor cell invasion and growth at extrahepatic sites. Cell Death Dis 2018;9:249.

46. Zhang R, Zhang F, Sun Z, et al. LINE-1

Retrotransposition Promotes the Development and Progression of Lung Squamous Cell Carcinoma by Disrupting the Tumor-Suppressor Gene FGGY. Cancer Res 2019;79:4453-65.

47. Huang Z, Shi J, Gao Y, et al. HMDD v3.0: a database for experimentally supported human microRNA-disease associations. Nucleic Acids Res 2019;47:D1013-7.

48. Wong NW, Chen Y, Chen S, et al. OncomiR: an online resource for exploring pan-cancer microRNA dysregulation. Bioinformatics 2018;34:713-5.

49. Paraskevopoulou MD, Vlachos IS, Hatzigeorgiou AG. DIANA-TarBase and DIANA Suite Tools: Studying Experimentally Supported microRNA Targets. Curr Protoc Bioinformatics 2016;55:12.14.1-12.14.18.

50. Agarwal V, Bell GW, Nam JW, et al. Predicting effective microRNA target sites in mammalian mRNAs. Elife 2015;4:e05005.
51. Zhang J, Ratanasirintrawoot S, Chandrasekaran S, et al. LIN28 Regulates Stem Cell Metabolism and Conversion to Primed Pluripotency. Cell Stem Cell 2016;19:66-80.

52. Leon G, MacDonagh L, Finn SP, et al. Cancer stem cells in drug resistant lung cancer: Targeting cell surface markers and signaling pathways. Pharmacol Ther 2016;158:71-90.

53. Eramo A, Haas TL, De Maria R. Lung cancer stem cells: tools and targets to fight lung cancer. Oncogene 2010;29:4625-35.

54. Yan Z, Wang Q, Lu Z, et al. OSluca: An Interactive Web Server to Evaluate Prognostic Biomarkers for Lung Cancer. Front Genet 2020;11:420.

55. Győrffy B, Surowiak P, Budczies J, et al. Online survival analysis software to assess the prognostic value of biomarkers using transcriptomic data in non-small-cell lung cancer. PLoS One 2013;8:e82241.

56. Wang L, Liu X, Ren Y, et al. Cisplatin-enriching cancer stem cells confer multidrug resistance in non-small cell lung cancer via enhancing TRIB1/HDAC activity. Cell Death Dis 2017;8:e2746.

57. Mittal V. Epithelial Mesenchymal Transition in Tumor Metastasis. Annu Rev Pathol 2018;13:395-412.

58. Lee H, Han S, Kwon CS, et al. Biogenesis and regulation of the let-7 miRNAs and their functional implications. Protein Cell 2016;7:100-13.

59. Sun X, Liu J, Xu C, et al. The insights of Let-7 miRNAs in oncogenesis and stem cell potency. J Cell Mol Med 2016;20:1779-88.

60. Oliveira-Mateos C, Sánchez-Castillo A, Soler M, et al. The transcribed pseudogene RPSAP52 enhances the oncofetal HMGA2-IGF2BP2-RAS axis through LIN28Bdependent and independent let-7 inhibition. Nat Commun 2019;10:3979.

61. Gunzburg MJ, Sivakumaran A, Pendini NR, et al. Cooperative interplay of let-7 mimic and HuR with MYC RNA. Cell Cycle 2015;14:2729-33.

62. Guo L, Cheng X, Chen H, et al. Induction of breast cancer stem cells by M1 macrophages through Lin-28Blet-7-HMGA2 axis. Cancer Lett 2019;452:213-25.

63. Triboulet R, Pirouz M, Gregory RI. A Single Let-7 MicroRNA Bypasses LIN28-Mediated Repression. Cell Rep 2015;13:260-6.

64. Yu J, Vodyanik MA, Smuga-Otto K, et al. Induced pluripotent stem cell lines derived from human somatic cells. Science 2007;318:1917-20.

65. Zhan M, Qu Q, Wang G, et al. Let-7c inhibits NSCLC cell proliferation by targeting HOXA1. Asian Pac J Cancer 
Prev 2013;14:387-92.

66. Zhao B, Han H, Chen J, et al. MicroRNA let-7c inhibits migration and invasion of human non-small cell lung cancer by targeting ITGB3 and MAP4K3. Cancer Lett 2014;342:43-51.

67. Wang PY, Sun YX, Zhang S, et al. Let-7c inhibits A549 cell proliferation through oncogenic TRIB2 related factors. FEBS Lett 2013;587:2675-81.

68. Sun X, Xu C, Tang SC, et al. Let-7c blocks estrogenactivated Wnt signaling in induction of self-renewal of breast cancer stem cells. Cancer Gene Ther 2016;23:83-9.
69. Takebe N, Miele L, Harris PJ, et al. Targeting Notch, Hedgehog, and Wnt pathways in cancer stem cells: clinical update. Nat Rev Clin Oncol 2015;12:445-64.

70. Katoh M, Katoh M. WNT signaling pathway and stem cell signaling network. Clin Cancer Res 2007;13:4042-5.

71. Tsanov KM, Pearson DS, Wu Z, et al. LIN28 phosphorylation by MAPK/ERK couples signalling to the post-transcriptional control of pluripotency. Nat Cell Biol 2017;19:60-7.

(English Language Editor: J. Reynolds)

Cite this article as: Zhang R, Liu P, Zhang X, Ye Y, Yu J. Lin28A promotes the proliferation and stemness of lung cancer cells via the activation of mitogen-activated protein kinase pathway dependent on microRNA let-7c. Ann Transl Med 2021;9(12):982. doi: 10.21037/atm-21-2124 


\section{Sphere formation assay}

For the sphere formation assay, we deposited cells into 6-well plates (Corning, NYC, NY, USA) containing serumfree Dulbecco's Modified Eagle Medium with $10 \mathrm{ng} / \mathrm{mL}$ fibroblast growth factor 2 (bFGF), $20 \mathrm{ng} / \mathrm{mL}$ epidermal growth factor (EGF), $5 \mu \mathrm{g} / \mathrm{mL}$ insulin and $0.4 \%$ Bovine Serum Albumin (BSA). After a 10-day incubation period, we counted the spheres formed using a microscope. Experiments were performed in triplicate $(\mathrm{N}=3$ in each group).

\section{Cell Apoptosis Analysis}

The Annexin-V-FITC Apoptosis Detection kit was used to measure apoptosis. After 24 hours starvation treatment, cells were washed with PBS and resuspended in $1 \times$ binding buffer at a concentration of $1 \times 10^{6}$ cells/ml. Subsequently, $5 \mu \mathrm{l}$ of Annexin-V and $5 \mu \mathrm{l}$ of PI were added to $100 \mu \mathrm{l}$ of the cell suspension, and the mixture was incubated for $15 \mathrm{~min}$ in the dark. The analyses were performed using a flow cytometry. The experiments were repeated at least 3 times ( $\mathrm{N}=3$ in each group).

\section{Wound healing assay}

We carried out the wound healing assay by first seeding cells in 6-well plates and leaving them for 24 hours. After the cells had reached $80 \sim 90 \%$ confluency, a $10-\mu$ pipette tip was used to make a straight line in the cell monolayer. Phosphate-buffered saline (PBS) was used to remove cell debris and the wounded cells were subjected to culture in fresh medium. At 0 and 48 hours, images were obtained, and the distance of the wound was measured. The cell migration rate was calculated as the distance of the wound at 0 hours - the distance of the wound after 48 hours)/the distance of the wound at 0 hours $\times 100 \%$. The experiments were repeated at least 3 times. Experiments were performed in triplicate ( $\mathrm{N}=3$ in each group).

\section{Transwell invasion assay}

We performed assays to assess the invasive ability of cells by using Matrigel and Transwells (BD Biosciences, San Jose, CA, USA) to construct invasion chambers for the separation of cells with high and low invasion ability. After seeding cells in Matrigel and $100 \mu$ serum-free RPMI1640 at a density of $1 \times 10^{5}$ in 24-well Transwell plates with a 8 - $\mu \mathrm{m}$ pore size polycarbonate filter membrane (Corning, NYC, NY, USA). Medium supplemented with $10 \%$ FBS was placed in the lower chamber of the Transwell. After 48 hours' incubation, we used methanol to fix the cells on the membrane's lower surface and then subject them to staining with $1 \%$ toluidine blue. After staining photographs of the membrane were taken under a microscope, and the number of invading cells was recorded. Experiments were performed in triplicate ( $\mathrm{N}=3$ in each group).

\section{In vivo tumorigenicity experiment}

After the mice construction, we monitored tumor growth at 3 -day intervals. There were 5 mice in each group $(\mathrm{N}=5$ in each group). Each experiment was performed in triplicate. For each animal, three different investigators were involved as follows: a first investigator administered different cells into the flanks of mice via subcutaneous injection based on the randomization criteria. This investigator was the only person aware of the construction group allocation. A second investigator was responsible for monitoring tumor growth at 3 -day intervals. Finally, when the tumor size reached $1 \mathrm{~cm}^{3}$, a third investigator sacrificed the mice and collected all the tumors from mice. The following formula was applied to calculate the tumor volume $(\mathrm{V}): \mathrm{V}=3.14 \times \mathrm{L} \times \mathrm{W} \times \mathrm{H} / 6$ (L: length, W: width, H: height). The Ethics Committee for Animal Experiments of the Tianjin Medical University Cancer Hospital and Institute granted its approval for the animal experimental protocol used in this research, and all experiments were carried out in adherence with the National Institutes of Health Guide for the Care and Use of Laboratory Animals.

\section{Western blot}

Radioimmunoprecipitation assay buffer was used for the extraction of total protein. We subjected total protein (an approximate amount of $30 \mu \mathrm{g}$ ) to electrophoresis in a $12 \%$ sodium dodecylsulfate polyacrylamide gel before transferring the separated proteins to polyvinylidene difluoride membranes. After being blocked in 5\% BSA for 
1 hour at room temperature, the membranes were subjected to incubation overnight with the primary antibody at $4{ }^{\circ} \mathrm{C}$ at dilution ratios from 1:1,000 to 1:2,000. We bought rabbit anti-human Lin28A, Lin28B, GAPDH, ERK, p-ERK, JNK, p-JNK, P38, and p-P38 mABs from Cell Signaling Technology (CST, Danvers, MA, USA). The membranes were subjected to three 5-minute washes with tris-buffered saline with $0.05 \%$ Tween 20 (TBST), followed by 1-hour incubation with horseradish peroxidase-conjugated secondary antibody (1:4,000; Danvers, MA, USA) at room temperature. After 5 more 10-minute washes with TBST, we added enhanced chemiluminescence reagent to the membranes for the development of specific bands, and then used film for band visualization. Proteins were detected with the Chemi-Doc XRS Detection System (Bio-Rad, Hercules, CA, USA). Relative band density was analyzed with GAPDH/Actin serving as an internal reference.

\section{RNA extraction, Reverse Transcription- Polymerase Chain Reaction (RT-PCR), and quantitative Real-time PCR (qPCR) analysis}

A TRIzol kit (Invitrogen, Grand Island, NY, USA) was employed for the extraction of total RNA in adherence with the instructions supplied by the manufacturer. Electrophoresis was used to determine the RNA's integrity. Spectrophotometry was adopted for the analysis of RNA concentration and purity. RNA samples were stored at $-80{ }^{\circ} \mathrm{C}$. For synthesis of complementary DNA, we used equal quantities of total RNA $(1 \mu \mathrm{g})$ in a $20-\mu \mathrm{L}$ reverse transcriptase reaction mixture (Takara, Tokyo, Japan) For qPCR analysis, SYBR Premix Ex Taq ${ }^{\mathrm{TM}}$ (Takara, Tokyo, Japan) was used to detect amplified complementary DNA on a 7500 Real-Time PCR System (Applied Biosystems, Foster City, CA, USA). The primers used are shown in Table S1. $\beta$-actin and HsnRNA U6 (GeneCopoeia, Guangzhou, China) served used as internal controls for
mRNA expression and miRNA expression, respectively. For each sample, experiments were performed 3 times ( $\mathrm{N}=3$ in each group), and the $\Delta \mathrm{CT}$ method was adopted. The relativemRNA and miRNA levels in each sample were calculated as $2^{-\Delta \mathrm{CT}}\left(\Delta \mathrm{CT}=\mathrm{CT}_{\text {target gene }}-\mathrm{CT}_{\text {reference gene. }}\right)$.

\section{Dual-luciferase reporter assay}

The interplay between Lin28A/B and let-7c was assessed by dual-luciferase reporter assay. The sequence of either Lin28A or Lin28B was subcloned into the psiCheck2.0 basic plasmid (Hanbio Co., Ltd., Shanghai, China). The mutant sequences of Lin28A/B (the mutant sides were located at the potential binding sites of Lin $28 \mathrm{~A} / \mathrm{B}$ and let7c) were also subcloned into the psiCheck 2.0 basic plasmid (MUTA). Then, the well-grown HEK-293T cells were cotransfected with Lin28A/B/MUTA and miR-NC/let-7c mimic. Two days after transfection, the relative luciferase activities of Lin28A/B and MUTA were examined using the dual-luciferase reporter assay system.

\section{Drug resistance assay}

In the Cell Counting Kit-8 (CCK-8) assay to detect half inhibitory concentration (IC50), we applied and compared the effect of varied doses of cisplatin. Cells were seeded at a density of $1 \times 10^{4}$ per well in a 96-well plate, and varied doses of cisplatin mentioned were added. The cell proliferation was measured using CCK- 8 assay after $48 \mathrm{~h}$. The cell survival rate was calculated according to the following equation: cell survival rate $=$ OD value of experimental group/OD value of the blank control group $\times 100 \%$. Cell inhibition rate $=1-$ cell survival rate. The linear regression was used to analyze the correlation between cisplatin concentration and cell inhibition rate, and calculated the IC50 values of different cells. The experiments were repeated at least 3 times ( $\mathrm{N}=3$ in each group). 


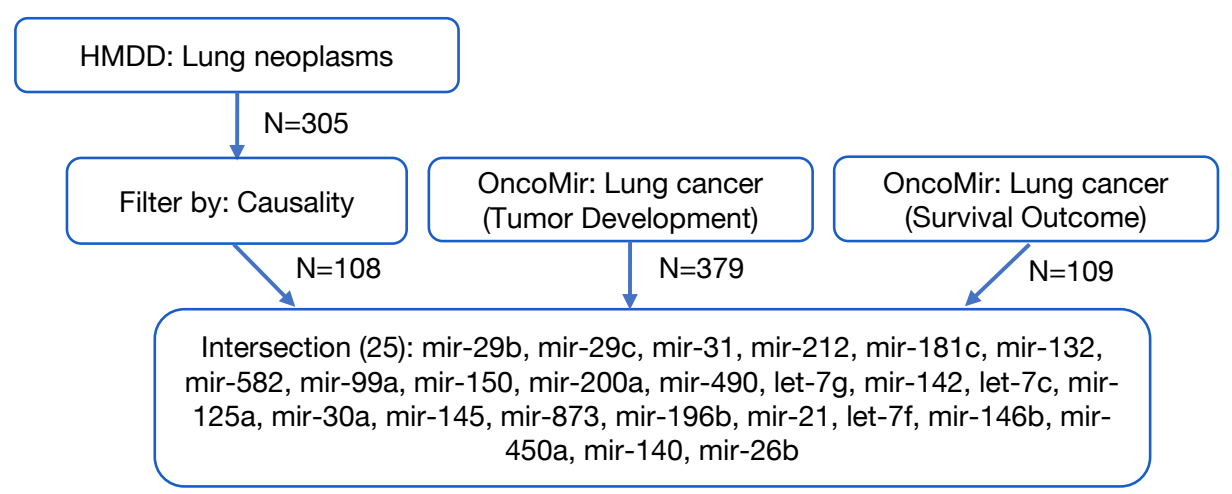

Figure S1 The workflow for filtering the most critical microRNAs (miRNAs) involved in lung cancer development in online databases.

A

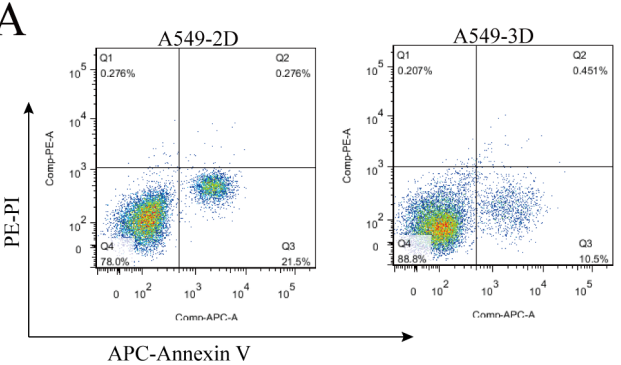

C

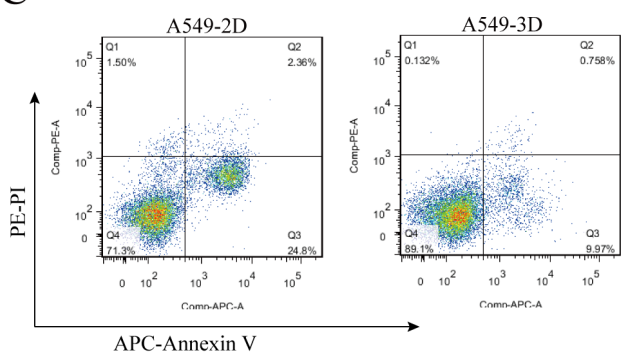

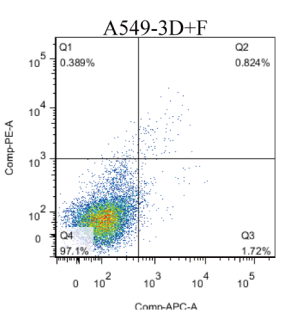

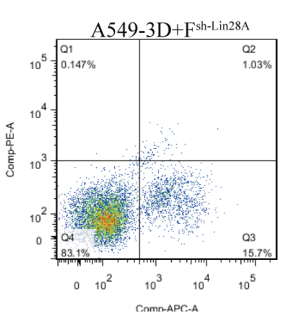

B

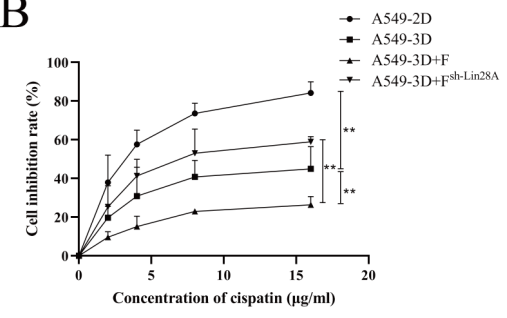

D
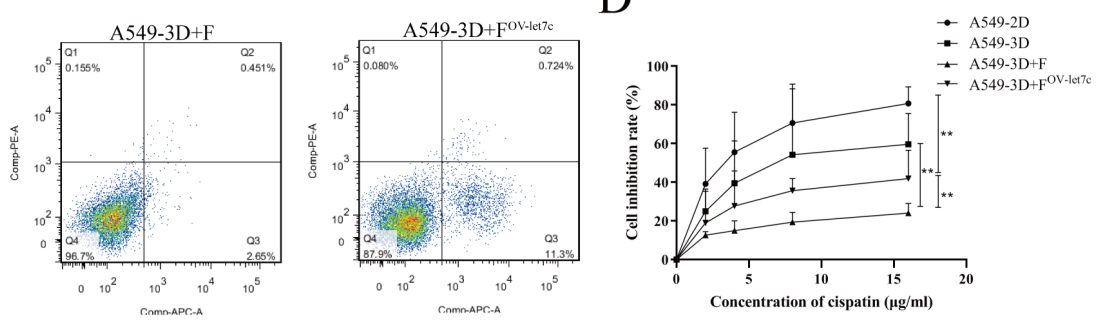

Figure S2 Knockdown of Lin28A or over-expression of let-7c weakened the resistance to apoptosis and chemotherapy drugs of lung cancer stem cells (LCSCs). (A) Results of Annexin-V apoptosis assays among A549 cells from the 2D culture (A549-2D cells), A549 cells from the 3D culture (A549-3D cells), A549 cells from the 3D culture with growth factors (A549-3D+F cells), and A549 cells over-expressing let-7c from the 3D culture with growth factors (A549-3D+F $\mathrm{F}^{\text {OV-let7c }}$ cells). (B) A549 cells from 4 groups were treated with several doses of cisplatin. The linear regression was drawn by drug concentration ( $\mathrm{X}$ axis) and cell growth inhibition rate ( $\mathrm{Y}$ axis) and half inhibitory concentration (IC50) was obtained. (C) Results of Annexin-V apoptosis assays among A549-2D, A549-3D, A549-3D+F, and A549 cells knockdown of Lin28A from the 3D culture with growth factors (A549-3D+F $\mathrm{F}^{\text {sh-Lin28A }}$ cells). (D) A549 cells from 4 groups were treated with several doses of cisplatin, followed by calculated IC50. 
Table S1 Primer sequences for realtime quantitative PCR (RT-qPCR)

\begin{tabular}{|c|c|c|}
\hline Gene/miRNA & Forward primer & Reverse primer \\
\hline Lin28A & 5'-ACAATGGGTGGGGGCTATTC-3' & 5'-GTGTGAACCCAAGCCTGAGA-3' \\
\hline Lin28B & 5'-GCCCCTTGGATATTCCAGTC-3' & 5'-TGACTCAAGGCCTITGGAAG-3' \\
\hline $\mathrm{N}$-cadherin & 5'-ACAGTGGCCACCTACAAAGG-3' & 5'-CCGAGATGGGGTTGATAATGC -3' \\
\hline$\beta$-catenin & 5'-TGGTGACAGGGAAGACATCA-3' & 5'-CCATAGTGAAGGCGAACTGC-3' \\
\hline Slug & 5'-TGCCTGTCATACCACAACCAGA-3' & 5'-GGAGGAGGTGTCAGATGGAGGA -3' \\
\hline Zeb1 & 5'-ACCTGCCAACAGACCAGACAGT-3' & 5'-ACATCCTGCTTCATCTGCCTGAG-3' \\
\hline Twist1 & 5'-ACTTCCTCTACCAGGTCCTCCAG-3' & 5-ССТССАТССТССАGACCGAGAA-3' \\
\hline Oct4 & 5'-TCCACTTTGTATAGCCGCTGG-3' & 5'-TGCATACACACAAACACAGCAA-3' \\
\hline miR-29b-5p & 5'-CTGGTTTCACATGGTGGCTTAG-3' & 5'-GAACATGTCTGCGTATCTC-3' \\
\hline $\operatorname{miR}-29 c-3 p$ & 5'-TAGCACCATTTGAAATCGGTTA-3' & 5'-GAACATGTCTGCGTATCTC-3' \\
\hline miR-31-3p & 5'-TGCTATGCCAACATATTGCCAT-3' & 5'-GAACATGTCTGCGTATCTC-3' \\
\hline miR-212-3p & 5'-TAACAGTCTCCAGTCACGGCC-3' & 5'-GAACATGTCTGCGTATCTC-3' \\
\hline $\operatorname{miR}-181 c-5 p$ & 5'-AACATTCAACCTGTCGGTGAGT-3' & 5'-GAACATGTCTGCGTATCTC-3' \\
\hline miR-132-3p & 5'-TAACAGTCTACAGCCATGGTCG-3' & 5'-GAACATGTCTGCGTATCTC-3' \\
\hline miR-582-5p & 5'-TTACAGTTGTTCAACCAGTTACT-3' & 5'-GAACATGTCTGCGTATCTC-3' \\
\hline miR-99a-5p & 5'-AACCCGTAGATCCGATCTTGTG-3' & 5'-GAACATGTCTGCGTATCTC-3' \\
\hline let-7c-5p & 5'-TGAGGTAGTAGGTTGTATGGTT-3' & 5'-GAACATGTCTGCGTATCTC-3' \\
\hline$m i R-125 a-5 p$ & 5'-TCCCTGAGACCCTTTAACCTGTGA-3' & 5'-GAACATGTCTGCGTATCTC-3' \\
\hline miR-30a-5p & 5'-TGTAAACATCCTCGACTGGAAG-3' & 5'-GAACATGTCTGCGTATCTC-3' \\
\hline miR-145-3p & 5'-GGATTCCTGGAAATACTGTTCT-3' & 5'-GAACATGTCTGCGTATCTC-3' \\
\hline miR-873-5p & 5'-GCAGGAACTTGTGAGTCTCCT-3' & 5'-GAACATGTCTGCGTATCTC-3' \\
\hline miR-196b-5p & 5'-TAGGTAGTTTCCTGTTGTTGGG-3' & 5'-GAACATGTCTGCGTATCTC-3' \\
\hline$m i R-21-5 p$ & 5'-TAGCTTATCAGACTGATGTTGA-3' & 5'-GAACATGTCTGCGTATCTC-3' \\
\hline let-7f-3p & 5'-CTATACAGTCTACTGTCTTTCC-3' & 5'-GAACATGTCTGCGTATCTC-3' \\
\hline$m i R-146 b-3 p$ & 5'-GCCCTGTGGACTCAGTTCTGGT-3' & 5'-GAACATGTCTGCGTATCTC-3' \\
\hline $\operatorname{miR}-450 a-5 p$ & 5'-TTTTGCGATGTGTTCCTAATAT-3' & 5'-GAACATGTCTGCGTATCTC-3' \\
\hline $\operatorname{miR}-140-5 p$ & 5'-CAGTGGTTTTACCCTATGGTAG-3' & 5'-GAACATGTCTGCGTATCTC-3' \\
\hline miR-26b-3p & 5'-CCTGTTCTCCATTACTTGGCT-3' & 5'-GAACATGTCTGCGTATCTC-3' \\
\hline U6 & 5'-CGCTTCGGCAGCACATATAC-3' & 5'-CAGGGGCCATGCTAATCTT-3' \\
\hline$\beta$-actin & 5'-TGGTGACAGGGAAGACATCA-3' & 5'-CCATAGTGAAGGCGAACTGC-3' \\
\hline
\end{tabular}

